\title{
Impact of the Summer Monsoon Westerlies on the South China Sea Tropical Cyclone Genesis in May ${ }^{0}$
}

\author{
Tsing-Chang Chen AND JenQ-DaR Tsay \\ Department of Geological and Atmospheric Sciences, Iowa State University, Ames, Iowa \\ Jun MATSUMOTO \\ Department of Geography, Tokyo Metropolitan University, Tokyo, and Department of Coupled \\ Ocean-Atmosphere-Land Processes Research, JAMSTEC, Yokosuka, Japan \\ JORDAN ALPERT \\ National Centers for Environmental Predication/Environmental Modeling Center, College Park, Maryland
}

(Manuscript received 31 October 2016, in final form 28 January 2017)

\begin{abstract}
After the onset of the Southeast Asian summer monsoon in mid-May, the South China Sea (SCS) trough is deepened by the intensified monsoon westerlies to facilitate the development of a synoptic cyclonic shear flow. This shear flow forms an environment favorable for the SCS tropical storm (TS)/typhoon (TY) genesis triggered by the surge of this monsoon circulation. This genesis mechanism has not been well documented. Seventeen named SCS TS/TY geneses in May over 1979-2016 occurred under the following environmental conditions/processes: 1) with its maximum located south of $15^{\circ} \mathrm{N}$, the intensified monsoon westerlies are extended eastward beyond $\left.120^{\circ} \mathrm{E}, 2\right)$ the synoptic SCS cyclonic shear flow is developed by the tropical easterlies fed by a northeast Asian cold surge (or a North Pacific cold-air outbreak) and the intensified monsoon westerlies, and 3) SCS TS/TY genesis is triggered by the surge of monsoon flow. The accuracy of the monthly mean forecasts is limited. However, it is found that SCS TS/TY genesis only occurs after the existence of persistent, strong, monsoon westerlies lasting for at least 5 days. Forecasts from the National Centers for Environmental Prediction Global Forecast System (2004-16) and the Global Ensemble Forecast System (1985-2003) cover these 15 SCS TS/TY geneses. The requirements for SCS TS/TY genesis in May described above are met by the 5-day-mean Southeast Asian summer monsoon circulation. Based on a statistical analysis of 5-day forecasts for these TS/TY geneses, a four-step forecast advisory is introduced. The forecasts for SCS TS/TY genesis can be made 3 days prior to occurrence.
\end{abstract}

\section{Introduction}

The typhoon season for East Asia and the northern part of Southeast Asia usually starts after the monsoon break in late June-early July (Ramage 1952; Chen et al. 2004a). Therefore, most typhoon (TY) research efforts focus on the TY season. May is a transition month of the East-Southeast Asian monsoon, as the

Supplemental information related to this paper is available at the Journals Online website: http://dx.doi.org/10.1175/ WAF-D-16-0189.s1.

Corresponding author e-mail: Tsing-Chang (Mike) Chen, tmchen@iastate.edu retreat of the winter monsoon northwesterlies, and the intrusion of the summer monsoon southwesterlies lead to the development of the South China Sea (SCS) trough and the onset of the summer monsoon. Because of the strengthening of the monsoon westerlies, some geneses of tropical storms (TSs) and TYs may occur in the SCS during May. Numerous studies have been made into various aspects of SCS TS/TY activity (e.g., Wang et al. 2007, Goh and Chan 2009; Chen 2011; Chen et al. 2015), but SCS TS/TY genesis in May has not been a focus of previous studies. In reality, an unexpected tropical storm during May could bring a hazardous weather system to the busy ship routes in the SCS. Therefore, it is important for us to understand under what climate/synoptic conditions 
tropical cyclone genesis is likely to occur and to forecast those conditions in advance.

On 12 May 2008, the summer monsoon onset date of the west Philippines, geneses of twin tropical depressions (TDs) occurred in the SCS within $12 \mathrm{~h}$ south of $15^{\circ} \mathrm{N}$ between central Vietnam and the Philippines. These two TDs eventually developed into TY Halong and TS Matmo. Three special features concerning the geneses of these two TDs were observed in our previous study (Chen et al. 2010):

1) Impact of the Southeast Asian monsoon circulation change-the SCS monsoon trough is oriented northwest-southeast between northeast Indochina and northwest Borneo. The deepening of this trough not only strengthens the eastward intrusion of monsoon westerlies beyond $120^{\circ} \mathrm{E}$, but also shifts the maximum monsoon westerlies to south of $15^{\circ} \mathrm{N}$. This change in the Southeast Asian monsoon circulation enables these twin TDs to propagate eastward across the Philippines during their initial phase. After crossing the Philippines, these two TDs moved northeastward along the anomalous cyclonic shear flow east of the western North Pacific island chain.

2) Formation of an incubator for the Philippines twin TDs-during the summer monsoon onset of the west Philippines, a synoptic-scale cyclonic shear zone develops between central Vietnam and the Philippines through the intersection of a northeast Asian cold-surge-like flow and the southward-shifted intensified monsoon westerlies. This cyclonic shear zone forms a favorable environment for geneses of the Philippines twin TDs.

3) Triggering mechanism of twin TD geneses-temporally in-phase surges of the northeast Asian cold-surge-like flow and the monsoon westerlies lead to the spinup of embryo vortices within the SCS cyclonic shear flow to form the twin TDs in the Philippines.

A revised time-longitude $(x-t)$ diagram of $850-\mathrm{hPa}$ zonal wind at the maximum $u(850 \mathrm{hPa})$ latitude superimposed with TDs (typhoon symbols) and monsoon vortices (filled circles) presented by Chen et al. (2010) is revised to cover 38 months of May for the 1979-2016 period and results are shown in Fig. 1. The geneses of a total of 17 TDs are identified, and these TDs developed into named TSs or TYs. The following two questions are raised from these statistics:

1) The TD genesis mechanism occurs over the western tropical Pacific and may be caused by different mechanisms: an interaction of a tropical easterly wave either with the monsoon gyre (Chen et al. 2004b), with the western tropical Pacific trough
(Wu et al. 2012, 2014), or with a tropical cyclone shear and confluence (Ritchie and Holland 1999), etc. Because the genesis mechanism of the Philippine twin TDs differs from the TD genesis mechanisms over the western tropical Pacific, can geneses of the other 15 SCS TDs in May occur under climate conditions for the Southeast Asian monsoon circulation, a favorable synoptic environment in the SCS, and triggering mechanisms impacted by surges of the monsoon westerly flow and the northeast Asian cold-surge-like flow, similar to the genesis of the Philippine twin TDs?

2) Since 2003, the operational forecasts of tropical cyclone (TC) tracks and intensities were extended by the U.S. National Hurricane Center. Thus, the need to extend the TC formation forecast is intensified. The statistical-dynamic forecast tools provide the probabilistic TC genesis forecast over the western North Pacific, the east Pacific basin, and the Atlantic basin introduced by recent studies (e.g., Schumacher et al. 2009; Cossuth et al. 2013; Halperin et al. 2017). The SCS TC genesis in May occurs when the eastward intrusion of intensified monsoon westerlies reaches beyond $120^{\circ} \mathrm{E}$ and also shifts south of $15^{\circ} \mathrm{N}$. Thus, it is impractical to apply the statisticaldynamic approach to forecasting the SCS TC genesis during May. Is it possible to use answers to question 1 above to develop a simple forecast advisory for the occurrence of TD genesis during May in the SCS?

To investigate and find answers to these two questions, this study is organized in the following manner. Section 2 describes the data for this study. They include 1) locations of the SCS TS/TY geneses and their tracks archived by the Joint Typhoon Warning Center (JTWC) and the Japan Meteorological Agency (JMA), supplemented with JMA surface analysis charts, and 2) the National Centers for Environmental Prediction (NCEP) Tropical Strip Surface Analysis [Service Records Retention System (SRRS)], NCEP's Global Forecast System (GFS) (NCEP 2003; NWS/EMC 2016), the European Centre for MediumRange Weather Forecasts (ECMWF) interim reanalysis (ERA-Interim; Dee et al. 2011), and daily reforecasts issued by the Earth System Research Laboratory (ESRL)/ Physical Sciences Division (PSD) second-generation Reforecast Project (Hamill et al. 2013, 2016). Section 3 presents statistics from the analysis results for the environmental conditions favorable for SCS TS/TY genesis, including 1) interannual variation of the Southeast Asian monsoon westerlies, 2) development of the synoptic cyclonic shear flow across the SCS, and 3) surges of several components of the Southeast Asian monsoon circulation and its impact on the occurrence of SCS TS/TY genesis. By applying statistical results obtained in section 3 and 


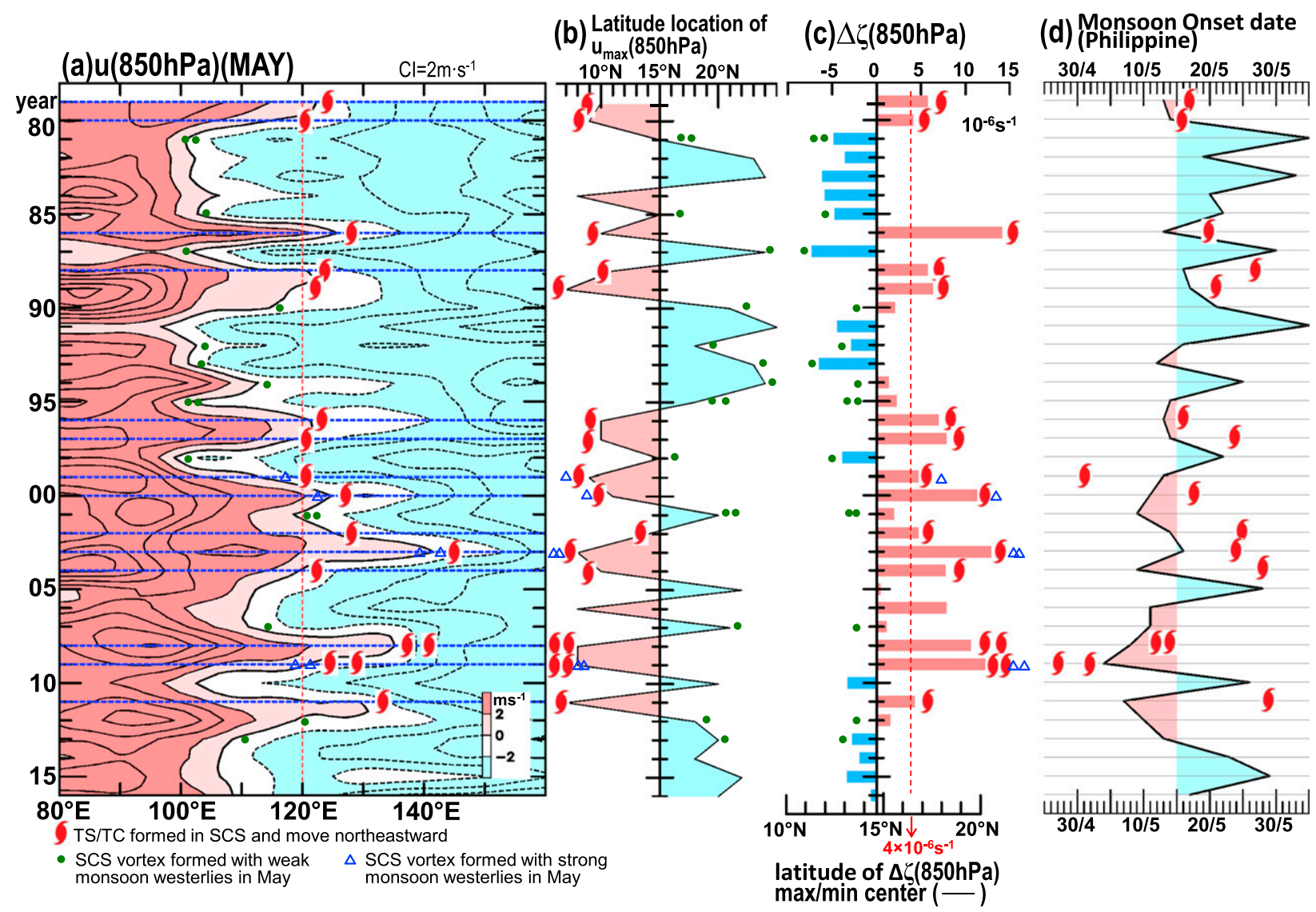

FIG. 1. (a) The $x-t$ diagram of monthly mean 850 -hPa monsoon westerly flows in May at the latitude of either its maximum westerly or easterly south of $15^{\circ} \mathrm{N}$. (b) The latitude of the maximum monthly mean 850-hPa monsoon westerly wind in May. (c) The area average of the $\Delta \zeta(850 \mathrm{hPa})$ anomaly averaged over the maximum (minimum) center surrounded by threshold values $\Delta \zeta(850 \mathrm{hPa}) \geq 10^{-6} \mathrm{~s}^{-1}\left(\leq 10^{-6} \mathrm{~s}^{-1}\right)$ in the SCS region $\left(10^{\circ} \sim 20^{\circ} \mathrm{N}, 110^{\circ} \sim 120^{\circ} \mathrm{E}\right)$. (d) The onset date of summer monsoons in the area around the southwest Luzon Islands, between $14^{\circ}$ and $16^{\circ} \mathrm{N}$. The months of May with the TS/TY genesis and formation of SCS vortices are marked by typhoon symbols and green dots, respectively. The SCS vortices formed in May of the strong monsoon westerly years are denoted by a blue open triangle.

forecasts from NCEP GFS and Global Ensemble Forecast System (GEFS), section 4 introduces a simple forecast advisory for the occurrence of SCS TS/TY genesis. Section 5 offers a summary and conclusions of this study, as well as suggestions for future study.

\section{Data}

Data used in this study include tracks of named TSs/TYs, global reanalyses, global forecasts, and rainfall totals measured by WMO surface stations. Some details of these datasets are described below.

\section{a. Genesis locations and tracks of named TSs/TYs}

The best tropical cyclone tracks issued by the Joint Typhoon Warming Center (JTWC 2016) are utilized to identify genesis locations of all SCS tropical cyclones and to trace their movements during the month of May over the period of 1979-2016. The JTWC genesis locations for a tropical cyclone identified in the SCS are verified against those archived by the JMA's Regional Specialized Meteorological Center-Tokyo (RSMC 2016), JMA surface analysis charts, and NCEP SRRS maps. Differences among these data sources are tracked with the $850-\mathrm{hPa}$ streamline chart prepared with reanalysis data in terms of two criteria:

1) The location of any tropical cyclone formation identified by JTWC or RSMC is tracked backward to the location of its first appearance with a closed vortex in the 850 -hPa streamline chart.

2) The maximum $\zeta(850 \mathrm{hPa})$ is identified with a value $\geq 2 \times 10^{-5} \mathrm{~s}^{-1}$ within its tropical cyclone encircled by a threshold value $\geq 10^{-5} \mathrm{~s}^{-1}$.

\section{b. Reanalysis data}

Reanalysis data generated by two data assimilation systems are used in the present study: 1) NCEP GFS and 
2) ECMWF ERA-Interim. They are global with a spatial resolution of $0.5^{\circ} \times 0.5^{\circ}$ and a temporal resolution of $6 \mathrm{~h}$. These two reanalysis datasets cover two different periods in this study: 2006-16 for the NCEP GFS reanalysis and 1979-2005 for ERA-Interim.

\section{c. Global forecasts}

It will be shown in section 3 that SCS TS/TY genesis in May only occurs when the monsoon westerly flow is strong. Thus, intensification of the SCS monsoon westerlies may be a feasible approach for predicting the potential for SCS TS/TY genesis during May. No current operational monthly mean forecast is available so far to provide the monsoon development 1 month prior to May. Therefore, a forecast advisory using the 5-day forecast to predict SCS TS/TY genesis 3 days ahead of its occurrence is introduced. Two global forecast systems are available to serve this purpose: the NCEP GFS (NCEP 2003; NWS/EMC 2016) and NCEP GEFS, version 2 (Hamill et al. 2013, 2016). The former forecast system issues an 8-day forecast with a 6-h temporal resolution and a $1^{\circ} \times 1^{\circ}$ spatial resolution for 2004-05 and a 16-day forecast with a 6-h temporal resolution and a $0.5^{\circ} \times 0.5^{\circ}$ spatial resolution for 2006-16. The latter forecast system produces the 8-day forecast with a 24-h (daily) resolution and a $1^{\circ} \times 1^{\circ}$ spatial resolution for 1985-2016.

\section{d. Measurements of rainfall and surface zonal winds at WMO surface stations along the west coast of the Philippines and Spratly Islands}

Daily accumulation rainfall and daily mean surface zonal winds measured by WMO stations along the western coast of the Philippines and in the Spratly Islands are utilized to define the monsoon onset date. The temporal resolution of rainfall and surface wind data is $3 \mathrm{~h}$, and the WMO station data cover the period 19792016.

The monsoon onset is generally defined by either the direction reversal of the steady ambient flow (e.g., Ramage 1971) or the sudden enhancement of rainfall (e.g., Ananthakrishnan and Soman 1988). These two criteria are used in this study to define the monsoon onset dates over the Manila area in the southwestern part of the Luzon Islands between $14^{\circ}$ and $16^{\circ} \mathrm{N}$, including six WMO surface stations (Cabanatuan, WMO station 98330; IBA/Luzon Islands, WMO station 98324; Clark International Airport, WMO station 98327; Science Garden, WMO station 98430; Manila, WMO station 98425; and Sangley Point, WMO station 98428). The direction reversal criterion needs steady westerlies maintained $\geq 10$ days. The sudden increase of the rainfall criterion requires $\geq 20 \mathrm{~mm} \mathrm{day}^{-1}$. The onset dates for other parts of the west coast are also defined in the supplementary material for this paper (see online supplement 1). Because the SCS monsoon intensity in May is determined by the monsoon westerlies south of $15^{\circ} \mathrm{N}$, the monsoon onset date over the Manila area is used in this study, instead of the definition used by the Philippine Atmospheric, Geophysical, and Astronomical Services Administration (PAGASA; Moron et al. 2009).

Important features and data sources described in this section are highlighted in Table 1.

\section{Environmental conditions for SCS TS/TY genesis in May}

\section{a. Monthly mean East-Southeast Asian monsoon circulation in May}

In May, the East-Southeast Asian monsoon circulation (Fig. 2a) south of $30^{\circ} \mathrm{N}$ is characterized by the eastwest juxtaposition of the continental thermal low and the North Pacific subtropical anticyclone. South of $20^{\circ} \mathrm{N}$, the low-level SCS circulation consists of a trough stretching from Myanmar, across the Gulf of Thailand and peninsula Malaysia, to central Sumatra, the SCS trough northeast of Borneo, and a confluent flow located in the northern SCS. As is revealed by the composite May 850-hPa streamline charts (Fig. 2b), three components of the East-Southeast Asian monsoon circulation pattern changed during the month of May with the occurrence of the TS/TY genesis (TY May). These include the eastward retreat of the North Pacific subtropical anticyclone out of SCS, the eastward shift of the welldeveloped monsoon trough, and the eastward migration of the confluent flow toward the east coast of the Luzon Islands. This circulation change during TY May (Fig. 2c) can be further highlighted by an anomalous cyclonic shear circulation pattern cyclonically surrounding the Asian continent from the head of the Bay of Bengal across Indochina and the Luzon-Taiwan-Japan chain of islands to the Japan Sea.

Supplemented with Fig. 1a, several salient features about the relationship between the genesis of TSs/TYs and interannual variation of the East-Southeast Asian monsoon are revealed in Fig. 2c:

1) Shown in Fig. 1a, the eastward intrusion/strengthening of the monsoon westerlies across $120^{\circ} \mathrm{E}$ essentially occurs south of $15^{\circ} \mathrm{N}$, as the monsoon westerly anomalies of the monsoon cyclonic shear circulation shown in Fig. 2c.

2) The SCS summer monsoon onset was defined by numerous studies (e.g., Chen and Chen 1995; Matsumoto 1997; Lau and Yang 1997; Zhou and Chan 2007) with two basic criteria: 1 ) the sudden onset of precipitation 


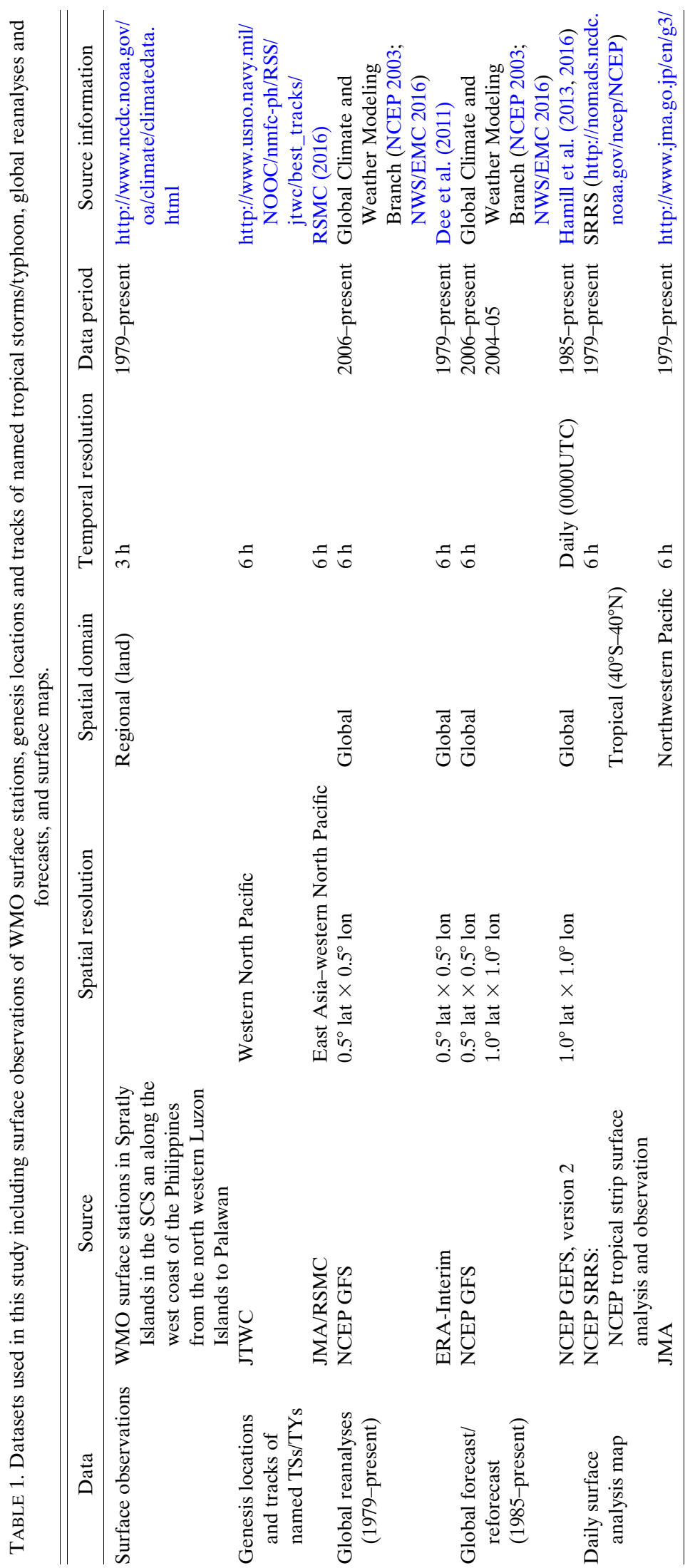



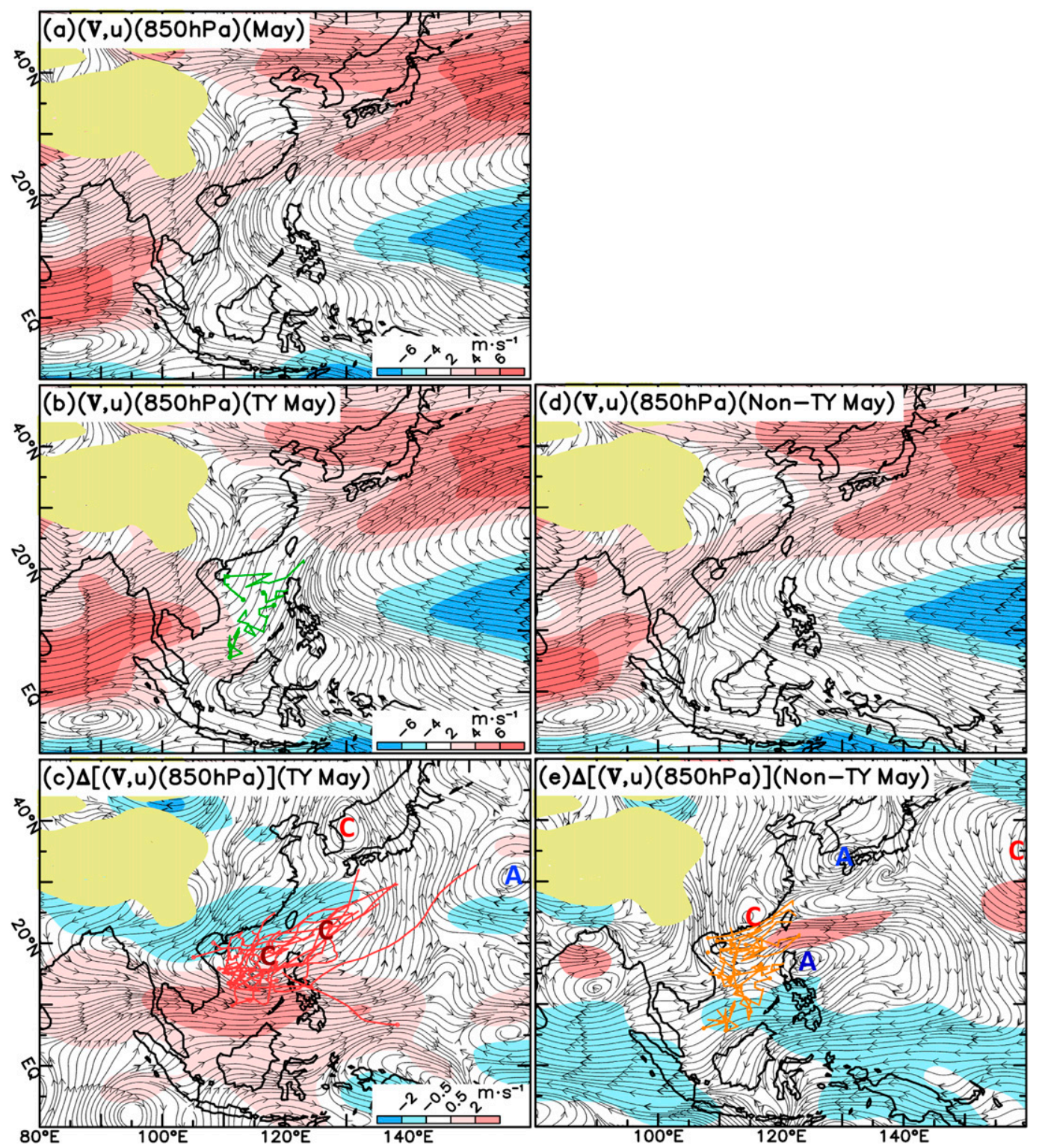

FIG. 2. (a) Climatology of the $\mathbf{V}(850 \mathrm{hPa})$ streamline chart in May superimposed with westerlies (red) and easterlies (blue). (b) Composited $\mathbf{V}(850 \mathrm{hPa}$ ) streamline chart in May with TS/TY genesis, superimposed with formation locations (green dots) and tracks (green lines) of SCS vortices. (c) Anomalous $\Delta \mathbf{V}(850 \mathrm{hPa})$ streamline charts in May constructed by superimposing (b) onto (a) with genesis locations of TSs/TYs (red dot) and tracks (red lines) of these TSs/TYs. (d),(e) As in (b),(c), but for non-TY/TS May. The formation locations of SCS vortices (gold dots) and tracks (gold lines) for these vortices are superimposed onto (e).

and 2) the switch of low-tropospheric easterlies to westerlies. Observed by the latter two studies, the SCS monsoon onset occurs earlier (later) if the SCS monsoon westerlies are stronger (weaker). The coincidence between strong monsoon westerlies (Fig. 1a) and the early SCS monsoon onset dates (Fig. 1d) provides a precursor for the SCS TSs/TYs. Additionally, the increase in TS/TY genesis during May after 1993/94 is consistent with the notable advance in the onset date of the summer monsoon over the west coast of the central Philippines, as observed by recent studies of the onset date of the SCS summer monsoon (Kajikawa and Wang 2012; Liu et al. 2016).

3) The enhancement of environmental vorticity by the monsoon cyclonic shear flow during May with strong monsoon westerlies (Fig. 1c) can facilitate the occurrence of SCS TS/TY genesis. The area-averaged $850-\mathrm{hPa}$ vorticity over the vorticity center in the 
southwest end of this cyclonic shear flow with a threshold value of $10^{-6} \mathrm{~s}^{-1}$ is shown by the histogram in Fig. 1c. This clearly shows that those months of May with the eastward intrusion of monsoon westerlies beyond $120^{\circ} \mathrm{E}$ have their $\zeta(850 \mathrm{hPa}) \geq 4 \times 10^{-6} \mathrm{~s}^{-1}$.

4) Because the cyclonic shear zone shown in Fig. $2 \mathrm{c}$ provides a favorable environment for TS/TY genesis, most geneses of the 17 identified TSs/TYs marked by red dots in the SCS are clustered over the southwest end of the composite cyclonic shear flow zone. Neumann (1993) classified these tracks of tropical cyclones originating in the tropics into two groups: 1) moving due westward to incur landfalls in the tropics and 2) moving westward to recurve in the midlatitudes and dissipate over land or ocean. Different from tracks of these two groups of typical cyclones, the SCS TSs/TYs in May follow the anomalous cyclonic shear flow. After their genesis, some SCS TSs/TYs may move eastward across the SCS and the Luzon Islands, and then northeastward along this cyclonic shear flow to the western North Pacific Ocean. Apparently, this anomalous cyclonic shear flow in May with the strong monsoon westerly not only functions as the incubator of the SCS TSs/TYs, but also regulates tracks for these TCs/TYs.

\section{b. Synoptic conditions for the formation of the SCS TCs in May}

Chen et al. (2010; their Fig. 6e, shown as the 850-hPa background flow in Fig. 4 of the present paper) illustrated the twin tropical cyclones that formed in the Philippines on 12 May 2008 through the tropical-midlatitude interaction of synoptic systems. A cyclonic shear flow between central Vietnam $(\mathrm{CV})$ and the Philippines $(\mathrm{PH})$ is formed by the easterlies to the north and the monsoon westerlies to the south of this shear flow. The easterlies originated from the cold-surge-like flow straddling a northeast Asian highlow dipole coupled with an upper-level trough across the eastern seaboard. The monsoon westerlies are partially fed by the cross-equatorial flow from easterlies of the tropical shear flow in the Southern Hemisphere. This cyclonic shear flow resembles the only premonsoon (May-June) season pattern (SP1) for the rapid intensification of tropical cyclones identified by Chen et al. (2015) during their premonsoon season of May-June.

The CV-PH cyclonic shear flow is overlaid by an upper-level residual anticyclone across Indochina, as shown in Fig. 6n of Chen et al. (2010). The cold-surge-like flow connecting this CV-PH cyclonic shear flow is coupled with an upper-level ridge behind the northeast Asian trough. This trough is separated from the tropical upward motion by the residual anticyclone across northern Indochina. The southward divergent flow from this anticyclonic zone is well developed by low-level updrafts.
Despite this separation, the twin TCs move eastward across the Philippines, and then move northeastward around the anomalous cyclonic shear flow, as shown in Fig. 2c, and catch the upper-level midlatitude trough.

In view of the formation of the twin TCs, two necessary/ required conditions are indispensable for the occurrence of SCS TC genesis in May:

1) the monthly mean anomalous cyclonic shear flow for May around the East-Southeast Asian region (Fig. 2c) caused by the deepening of the SCS trough and

2) SCS cyclonic shear flow that is formed by the easterlies of the northeast Asian cold-surge-like flow to the north and the intensified monsoon westerlies, which extend beyond $120^{\circ} \mathrm{E}$.

As shown in Fig. 1a and Table 1, geneses of the 17 SCS named TSs/TYs are identified in the 1979-2016 period when the monsoon westerlies are strengthened and extended beyond $120^{\circ} \mathrm{E}$. For the past $38 \mathrm{yr}$, the anomalous cyclonic shear flow, as depicted in Fig. 2c, appears during the month of May for $14 \mathrm{yr}$, when the geneses of TSs/TYs occur in the SCS. The first necessary/required condition is met by the 14 months of May (see online supplement 2 to this paper). The genesis of TY Cecil (row 17 in Table 2) was caused by the interaction of TY Brenda's wake low with the SCS trough in May, following its northwestwardpropagating parent TY Brenda. ${ }^{1}$ Because its genesis mechanism differs from other SCS TSs/TYs, TY Cecil is not considered a regular SCS TS/TY in the present study.

The synoptic conditions for TS/TY genesis (i.e., the second requirement) for the 17 named TSs/TYs include the synoptic development for the formation of a SCS cyclonic shear flow (see online supplement 3 to this paper). The easterlies north of the SCS cyclonic shear flow can originate from $t w o$ different types of synoptic systems for SCS TS/TY genesis during May:

1) easterlies originated from the northeast Asian coldsurge-like flow and

2) easterlies fed by the western North Pacific cold-air outbreak.

Of the 17 identified geneses for TSs/TYs in the SCS, 12 belong to type 1 cyclonic shear flow and 4 belong to type 2 cyclonic shear flow. The genesis for TY Cecil unusually occurred in an SCS cyclonic shear flow formed by the monsoon westerlies and the wake low of TY Brenda.

TS/TY geneses occurred in May in 14 yr during 19792016, when the East-Southeast Asian monsoon circulation

\footnotetext{
${ }^{1}$ TY Brenda genesis occurred at 1800 UTC 17 December 1989 at $6.7^{\circ} \mathrm{E}, 138.3^{\circ} \mathrm{E}$
} 
TABLE 2. The formation of cyclonic shear flow for the named TS/TY genesis in the SCS during the month of May over the 1979-2016 period, where (MW, EA) denotes strong monsoon westerlies, easterlies originating from the NE Asian cold-surge-like flow; (MW, EP) is strong monsoon westerlies and easterlies originating from the western North Pacific cold-air outbreak; and (MW, WL) is strong monsoon westerlies and wake low of TY Brenda.

\begin{tabular}{cllcc}
\hline \hline $\begin{array}{c}\text { No. of SCS TS/TY } \\
\text { genesis events }\end{array}$ & Name (category) & Genesis time & Location & $\begin{array}{c}\text { Type of cyclonic } \\
\text { shear }\end{array}$ \\
\hline 1 & Diding (TS) & 0000 UTC 17 May 1979 & $19.0^{\circ} \mathrm{N}, 112.7^{\circ} \mathrm{E}$ & $(\mathrm{MW}, \mathrm{EA})$ \\
2 & Georgia (TS) & 1800 UTC 16 May 1980 & $16.2^{\circ} \mathrm{N}, 110.5^{\circ} \mathrm{E}$ & $(\mathrm{MW}, \mathrm{EA})$ \\
3 & Mac (TS) & 1800 UTC 20 May 1986 & $15.5^{\circ} \mathrm{N}, 115.0^{\circ} \mathrm{E}$ & $(\mathrm{MW}, \mathrm{EA})$ \\
4 & Susan (TY-1) & 1800 UTC 27 May 1988 & $19.7^{\circ} \mathrm{N}, 117.2^{\circ} \mathrm{E}$ & $(\mathrm{MW}, \mathrm{EP})$ \\
5 & Cam (TS) & 0000 UTC 16 May 1996 & $13.5^{\circ} \mathrm{N}, 110.8^{\circ} \mathrm{E}$ & $(\mathrm{MW}, \mathrm{EP})$ \\
6 & Marie (TS) & 0000 UTC 23 May 1997 & $15.9^{\circ} \mathrm{N}, 109.3^{\circ} \mathrm{E}$ & $(\mathrm{MW}, \mathrm{EA})$ \\
7 & Leo (TY-3) & 0000 UTC 1 May 1999 & $15.1^{\circ} \mathrm{N}, 110.8^{\circ} \mathrm{E}$ & $(\mathrm{MW}, \mathrm{EA})$ \\
8 & Longwang (TS) & 0600 UTC 18 May 2000 & $20.0^{\circ} \mathrm{N}, 108.3^{\circ} \mathrm{E}$ & $(\mathrm{MW}, \mathrm{EA})$ \\
9 & Dagul (TS) & 0000 UTC 25 May 2002 & $17.7^{\circ} \mathrm{N}, 105.1^{\circ} \mathrm{E}$ & $(\mathrm{MW}, \mathrm{EA})$ \\
10 & Linfa (TS) & 1200 UTC 24 May 2003 & $16.3^{\circ} \mathrm{N}, 118.5^{\circ} \mathrm{E}$ & $(\mathrm{MW}, \mathrm{EA})$ \\
11 & Konsing (TS) & 1200 UTC 28 May 2004 & $8.9^{\circ} \mathrm{N}, 113.7^{\circ} \mathrm{E}$ & $(\mathrm{MW}, \mathrm{EP})$ \\
12 & Halong (TY-1) & 0000 UTC 12 May 2008 & $13.8^{\circ} \mathrm{N}, 111.9^{\circ} \mathrm{E}$ & $(\mathrm{MW}, \mathrm{EA})$ \\
13 & Matmo (TS) & 0600 UTC 12 May 2008 & $13.1^{\circ} \mathrm{N}, 118.0^{\circ} \mathrm{E}$ & $(\mathrm{MW}, \mathrm{EA})$ \\
14 & Kujira (TY-4) & 1800 UTC 27Apr 2009 & $13.3^{\circ} \mathrm{N}, 111.6^{\circ} \mathrm{E}$ & $(\mathrm{MW}, \mathrm{EA})$ \\
15 & Chan-hom (TY-2) & 1200 UTC 2 May 2009 & $10.9^{\circ} \mathrm{N}, 114.9^{\circ} \mathrm{E}$ & $(\mathrm{MW}, \mathrm{EP})$ \\
16 & Sarika (TS) & 0000 UTC 29 May 2011 & $13.9^{\circ} \mathrm{N}, 117.7^{\circ} \mathrm{E}$ & $(\mathrm{MW}, \mathrm{EA})$ \\
17 & Cecil (TY-1) & 0000 UTC 21 May 1989 & $11.7^{\circ} \mathrm{N}, 114.1^{\circ} \mathrm{E}$ & $(\mathrm{MW}, \mathrm{WL})$ \\
\hline
\end{tabular}

met the following continental-scale conditions and synoptic environment:

1) The departure of the monthly mean East-Southeast Asian circulation in May from its multiple-May mean circulation pattern exhibits an anomalous cyclonic shear flow around the East-Southeast Asian region with the following East-Southeast Asian circulation features:

(i) the eastward intrusion of the intensified monsoon westerlies reaches beyond $120^{\circ} \mathrm{E}$ and

(ii) the maximum speed of the monsoon westerlies across Indochina and the SCS shifts to latitudes south of $15^{\circ} \mathrm{N}$.

2) A synoptic cyclonic shear flow is formed in the SCS by the intensified monsoon westerlies and the tropical easterlies of the northeast Asian cold-surge flow.

In addition to the occurrence of 17 SCS TS/TY geneses in May during the strong monsoon westerlies, six SCS vortices ${ }^{2}$ form (Table 3 ). Tracks for these vortices are shown by the green lines in Fig. 2b. Regardless of the potential impact of the anomalous cyclonic shear

\footnotetext{
${ }^{2}$ The 850 - and 200-hPa streamline charts superimposed with zonal wind and vertical motion, respectively, at the formation for all 22 SCS vortices are shown in online supplement 4 . The SCS vortex is defined by four criteria. 1) A closed vortex appears over the SCS in the $850-\mathrm{hPa}$ streamline chart. 2) The area-averaged $\zeta(850 \mathrm{hPa})$ over a $4^{\circ} \times 4^{\circ}$ box of this vortex is $\geq 1.6 \times 10^{-5} \mathrm{~s}^{-1}$. 3) The life cycle is $\geq 1$ day. 4) The rainfall is $\geq 1 \mathrm{~mm} \mathrm{day}^{-1}$ within the $4^{\circ} \times 4^{\circ}$ box of the vortex.
}

flow around the East-Southeast Asian continent, these vortices are essentially trapped in the SCS. During nonTS/TY May, the North Pacific subtropical anticyclone extends somewhat southward into the SCS, weakening the monsoon westerlies (Fig. 2d). Consequently, the SCS TC/TY genesis is suppressed, but 16 SCS vortices formed (Table 3), regardless of the intensity of the monsoon westerlies. The anomalous circulation pattern for nonTY May is shown in Fig. 2e, a dipole structure (NW cyclone-SE anticyclone) across the northern SCS Tracks of the SCS vortices during non-TY May are presented as gold lines in Fig. 2e. As tracks of six SCS vortices during TS/TY May (Fig. 2b), tracks of the SCS vortices (during non-TY May) are also trapped in the SCS. The intensity evolutions of 17 SCS TSs/TYs and 22 SCS vortices measured with the area-averaged $\zeta(850 \mathrm{hPa})$ over the areas of their disturbances with a threshold value of $\zeta(850 \mathrm{hPa}) \geq 1.6 \times 10^{-5} \mathrm{~s}^{-1}$ are shown in Fig. 3. On day 0, intensities for some SCS strong monsoon westerly vortices during their formation stage may be comparable to those for some TSs/TYs during their genesis stage. In contrast, a clear distinction of intensity between TSs/TYs and SCS vortices emerges on day 1 . This intensity distinction offers an effective way to separate these two groups of SCS intense vortices.

\section{c. TS/TY genesis: Illustration of the spinup process with the vorticity budget analysis}

The synoptic environment favorable for SCS TS/TY genesis in May is the development of a cyclonic shear flow across the SCS from the interaction between the 
TABLE 3. Formation of cyclonic shear flow for SCS vortex formation in the SCS during the month of May over the 1979-2016 period, where (WW, EA) represents weak monsoon westerlies and easterlies originating from the NE Asian cold-surge-like flow; (WW, EP) is weak monsoon westerlies and easterlies originating from the western North Pacific cold-air outbreak; (MW, EA) denotes strong monsoon westerlies and easterlies originating from the NE Asian cold-surge-like flow; and (MW) is strong monsoon westerlies.

\begin{tabular}{lll}
\hline \hline \multicolumn{1}{c}{ Genesis time } & \multicolumn{1}{c}{ Location } & $\begin{array}{c}\text { Type of cyclonic } \\
\text { shear formed }\end{array}$ \\
\hline 0600 UTC 17 May 1981 & $16.5^{\circ} \mathrm{N}, 116.8^{\circ} \mathrm{E}$ & (WW, EA) \\
0000 UTC 21 May 1981 & $20.8^{\circ} \mathrm{N}, 108.2^{\circ} \mathrm{E}$ & (WW, EA) \\
0000 UTC 22 May 1985 & $6.0^{\circ} \mathrm{N}, 107.4^{\circ} \mathrm{E}$ & (WW, EP) \\
0600 UTC 17 May 1987 & $20.3^{\circ} \mathrm{N}, 111.9^{\circ} \mathrm{E}$ & (WW, EA) \\
0600 UTC 15 May 1990 & $8.7^{\circ} \mathrm{N}, 115.1^{\circ} \mathrm{E}$ & (WW, EP) \\
0600 UTC 26 May 1992 & $21.1^{\circ} \mathrm{N}, 115.0^{\circ} \mathrm{E}$ & (WW, EA) \\
0000 UTC 26 May 1993 & $20.3^{\circ} \mathrm{N}, 109.6^{\circ} \mathrm{E}$ & (WW, EA) \\
0600 UTC 5 May 1994 & $18.4^{\circ} \mathrm{N}, 108.1^{\circ} \mathrm{E}$ & (WW, EA) \\
0600 UTC 12 May 1995 & $18.4^{\circ} \mathrm{N}, 111.9^{\circ} \mathrm{E}$ & (WW) \\
1200 UTC 15 May 1995 & $18.9^{\circ} \mathrm{N}, 111.2^{\circ} \mathrm{E}$ & (WW, EA) \\
1200 UTC 25 May 1998 & $19.7^{\circ} \mathrm{N}, 114.3^{\circ} \mathrm{E}$ & (WW, EA) \\
0000 UTC 22 May 1999 & $7.6^{\circ} \mathrm{N}, 111.0^{\circ} \mathrm{E}$ & (MW) \\
0000 UTC 15 May 2000 & $18.8^{\circ} \mathrm{N}, 110.6^{\circ} \mathrm{E}$ & (MW) \\
1200 UTC 13 May 2001 & $14.4^{\circ} \mathrm{N}, 109.9^{\circ} \mathrm{E}$ & (WW) \\
1200 UTC 26 May 2001 & $17.9^{\circ} \mathrm{N}, 115.4^{\circ} \mathrm{E}$ & (WW) \\
1200 UTC 18 May 2003 & $14.2^{\circ} \mathrm{N}, 118.2^{\circ} \mathrm{E}$ & (MW) \\
0000 UTC 14 May 2003 & $5.7^{\circ} \mathrm{N}, 111.0^{\circ} \mathrm{E}$ & (MW) \\
1200 UTC 6 May 2007 & $15.1^{\circ} \mathrm{N}, 112.3^{\circ} \mathrm{E}$ & (WW, EA) \\
0600 UTC 22 May 2009 & $15.1^{\circ} \mathrm{N}, 113.2^{\circ} \mathrm{E}$ & (MW) \\
1200 UTC 30 May 2009 & $16.2^{\circ} \mathrm{N}, 116.5^{\circ} \mathrm{E}$ & (MW, EA) \\
0000 UTC 15 May 2012 & $14.2^{\circ} \mathrm{N}, 111.9^{\circ} \mathrm{E}$ & (WW, EA) \\
0600 UTC 2 May 2013 & $19.8^{\circ} \mathrm{N}, 111.9^{\circ} \mathrm{E}$ & (WW, EA) \\
\hline
\end{tabular}

easterly flow north of this shear flow and the monsoon westerly flow south of this shear:

1) The easterly flow exists along the southern periphery of the East Asian surface high pressure cell of the cold-surge-like dipole structure.

2) The tropical monsoon westerlies from the tropical Indian Ocean are partially fed by the crossequatorial tropical anticyclonic shear flow in the Southern Hemisphere (SH) tropics.

Previous studies (Gray 1998; Wu et al. 2015a,b) noted that the spinup process of TS/TY genesis may be caused by the interaction of the monsoon trough with the tropical easterly wave in the western North Pacific. In May, the easterly waves are prevented from moving westward into the SCS by strong monsoon westerlies. As observed by Chen et al. (2010), the twin TS/TY geneses in the Philippines are spun up from perturbations embedded in the SCS cyclonic shear flow by surges of both the easterlies and westerlies of this shear flow. Could this spinup mechanism lead to all $17 \mathrm{TS} / \mathrm{TY}$ geneses identified during May of 1979-2016? This question will be answered by exploring: 1) surges in both the easterlies (north) and westerlies (south) of the SCS cyclonic shear flow and
2) the spinup process of the TS/TY genesis illustrated with the vorticity budget analysis.

\section{1) SuRgeS IN THE SCS CYCLONIC SHEAR FLOW}

The synoptic conditions for the genesis of TY Halong (0000 UTC 12 May 2008) are depicted by the $850-\mathrm{hPa}$ streamline chart presented in Fig. 4, as an example to show the fact that surges are the most crucial synoptic elements of the SCS cyclonic shear flow (its shear line is indicated by a thick red-dashed line):

(i) The easterlies north of the SCS cyclonic shear flow $u_{\mathrm{EN}}$ are connected to the cold-surge-like flow that originated in northeast Asia $v_{\mathrm{NA}}$.

(ii) The monsoon westerlies south of the SCS cyclonic shear flow $u_{\mathrm{MW}}$ are partially fed by the cross-equator flow $v_{\mathrm{CE}}$ linked to the easterlies of the SH tropical trough $u_{\mathrm{ST}}$.

When a TS/TY genesis occurs, the locations of maximum speed for these two groups of flows at $850 \mathrm{hPa}$, $\left(v_{\mathrm{NA}}, u_{\mathrm{EN}}, u_{\mathrm{MW}}, v_{\mathrm{CE}}, u_{\mathrm{ST}}\right)(850 \mathrm{hPa})$, are marked by symbols explained at the bottom of Fig. 4. The time series of these flow speeds for every identified SCS TS/TY genesis is prepared with these flow speeds 5 days prior to and after genesis. These time series are displayed in Fig. 5. The time series of five flow speeds for TY Halong are presented by thick blue and red lines, respectively, for these two groups of flows: $\left(v_{\mathrm{NA}}, u_{\mathrm{EN}}\right)$ and $\left(u_{\mathrm{MW}}, v_{\mathrm{CE}}, u_{\mathrm{ST}}\right)$. It is clear that coherent surges emerge from the time series of these flow components. Apparently, the TY genesis for Halong occurs when a surge ${ }^{3}$ of the East-Southeast Asian monsoon takes place. Surges stand out in all of the time series of the five flow speeds for all $17 \mathrm{TS} / \mathrm{TY}$ geneses. Evidently, the surge of the East-Southeast Asian monsoon is a necessary factor for the occurrence of TS/TY genesis (see supplement 6 online).

\section{2) ILLUSTRATION OF THE SPINUP PROCESS WITH THE VORTICITY BUDGET}

The surge of the monsoon environmental flow is the basic mechanism that triggers the spinup process, leading to the occurrence of TS/TY genesis in the monsoon cyclonic shear flow across the SCS. The spinup process is reflected by the increase in vortex intensity measured by $\zeta(850 \mathrm{hPa})$. The response of airflow to the spinup process is the convergence of airflow to generate vertical motion $-\omega(850 \mathrm{hPa})$. The 11-day time series of these two variables area averaged over the TS/TY genesis vortex with

\footnotetext{
${ }^{3}$ The search for the surge mechanism of the Southeast Asian monsoon is beyond the scope of this study, but a constructive interference of monsoon modes (including 30-60-, 12-24-, 8-12-, and $3-8$-day modes) is suggested by the preliminary results presented in online supplement 5 .
} 


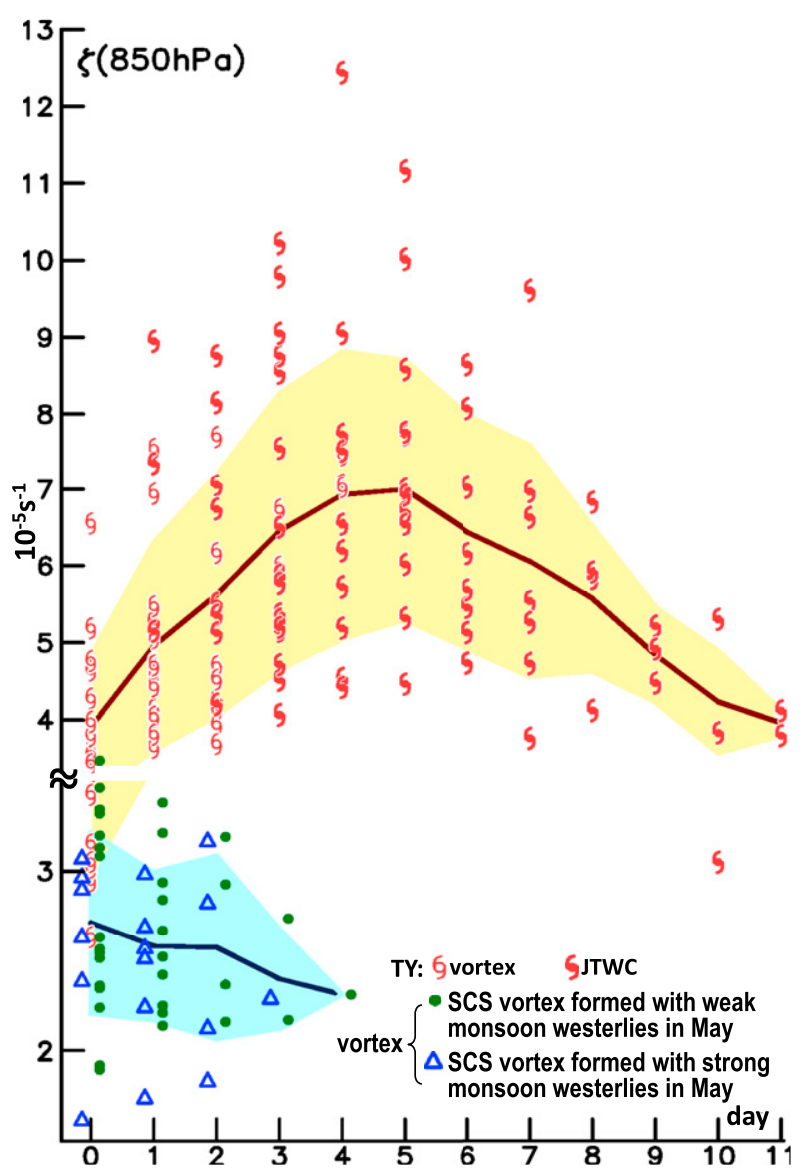

FIG. 3. Intensity evolution of all identified SCS TSs/TYs and vortices in May over their life cycles. Before being identified by JTWC as $\mathrm{TS} / \mathrm{TY}$, its parent tropical cyclone is denoted by an open typhoon symbol. The SCS vortex is denoted by a green dot. The blue open triangle is a vortex formed in May, when the monsoon westerlies are strong. Intensities of these TSs/TYs and vortices are measured by the area-averaged $\zeta(850 \mathrm{hPa})$ over the area with a threshold value of $\zeta(850 \mathrm{hPa}) \geq 1.6 \times 10^{-5} \mathrm{~s}^{-1}$. Daily mean intensities for SCS TSs/TYs and vortices are depicted by thick, dark brown and blue lines, respectively. The light yellow and blue strips added onto these two lines of daily mean intensities are one standard deviation of intensity with respect to their corresponding mean values each day.

their threshold values $\zeta(850 \mathrm{hPa}) \geq 2 \times 10^{-5} \mathrm{~s}^{-1}$ and $-\omega(850 \mathrm{hPa}) \geq 10^{-4} \mathrm{hPa} \mathrm{s}^{-1}$ for all $17 \mathrm{TS} / \mathrm{TY}$ geneses are shown in Fig. 6. In response to the surge of monsoon environmental flow, the spinup process of TS/TY genesis in the monsoon cyclonic shear flow is clearly indicated by peak values of both the $\zeta(850 \mathrm{hPa})$ and $-\omega(850 \mathrm{hPa})$ time series.

The spinup process of TS/TY genesis triggered by the surge of monsoon environmental flow is illustrated by the vorticity budget analysis:

$$
\begin{gathered}
\frac{\partial \zeta}{\partial t}=-\mathbf{V} \cdot \nabla(\zeta+f)-(\zeta+f) \nabla \cdot \mathbf{V} \\
\zeta_{t}^{C} \\
\zeta_{A}
\end{gathered} \quad \zeta_{V} .
$$

Chen et al. (2010) presented the $\zeta(850 \mathrm{hPa})$ budget analysis for TY Halong, and a condensed form is shown in Figs. 7a-c for the reader's convenience. The cyclonic shear flow embedded within TY Halong's genesis exhibits a positive $\zeta_{t}^{C}(850 \mathrm{hPa})$ vorticity tendency from the location of this TY genesis eastward. This positive $\zeta_{t}^{C}(850 \mathrm{hPa})$ tendency, a combination of $\zeta_{A}(850 \mathrm{hPa})$ and $\zeta_{V}(850 \mathrm{hPa})$, indicates $\zeta_{A}(850 \mathrm{hPa})$ is larger than $\left|\zeta_{V}(850 \mathrm{hPa})\right|$. In other words, $\zeta_{t}^{C}(850 \mathrm{hPa})$ is primarily contributed to by $\zeta_{A}(850 \mathrm{hPa})$ for this $\mathrm{TY}$ genesis. This contribution comparison between $\zeta_{A}(850 \mathrm{hPa})$ and $\zeta_{V}(850 \mathrm{hPa})$ reveals the importance of the former dynamic process. Apparently, the surge of the monsoon environmental flow that triggers TY Halong's genesis is reflected by the $\zeta(850 \mathrm{hPa})$ budget shown in Fig. $7 \mathrm{~d}$. The vorticity budget analysis clearly shows TY Halong's genesis is triggered by the spinup process; the surge of the monsoon flow dramatically strengthens the vorticity advection accompanied by positive vortex stretching.

Figure 7 illustrates the dynamic mechanism of the TS genesis through the spinup process. Is this dynamic mechanism for TY Halong genesis common to all identified cases of SCS TS/TY genesis during May? Both areaaveraged $\zeta_{A}(850 \mathrm{hPa})$ and $\zeta_{V}(850 \mathrm{hPa})$ over the genesis vortices with threshold values $\geq 1.5 \times 10^{-10} \mathrm{~s}^{-2}$ for all SCS TS/TY geneses during May are shown in the scatter diagram for $\zeta_{A}(850 \mathrm{hPa})$ versus $\zeta_{V}(850 \mathrm{hPa})$ in Fig. $8 \mathrm{a}$. The value of $\zeta_{A}(850 \mathrm{hPa})$ is always larger than the corresponding value of $\zeta_{V}(850 \mathrm{hPa})$. As shown in Fig. $8 \mathrm{~b}$, the $\zeta_{t}^{C}(850 \mathrm{hPa})$ values for all identified SCS TS/TY geneses in May are $\leq 10 \%$ error of the observed $\zeta_{t}^{o}(850 \mathrm{hPa})\left\{=\left[\zeta^{o}(t+6 \mathrm{~h})-\zeta^{o}(t-6 \mathrm{~h})\right] / 12 \mathrm{~h}\right\}$, as computed by the central finite-difference approach. The dynamic process of TY Halong illustrated by Chen et al. (2010) is applicable to all 17 SCS TSs/TYs in May.

To further confirm the spinup mechanisms for all identified SCS TS/TY genesis cases during May, the 11-day time series for $\zeta_{t}^{C}(850 \mathrm{hPa}), \zeta_{A}(850 \mathrm{hPa})$, and $\zeta_{V}(850 \mathrm{hPa})$ for all $17 \mathrm{TS} / \mathrm{TY}$ geneses are shown in Fig. 9. A peak value for all three time series emerges in response to the surge of the East-Southeast Asian monsoon. The spinup mechanism of SCS TS/TY genesis in May by the surge of this monsoon through the SCS cyclonic shear flow is further confirmed by the vorticity budget analysis.

\section{Forecast advisory for SCS TS/TY genesis in May}

May is a unique month for the transition of the Southeast Asian monsoon circulation from the cold-season monsoon northeasterlies into the warm-season monsoon southwesterlies. Because of this monsoon transition, it was observed in section 3 that SCS TS/TY genesis during May 


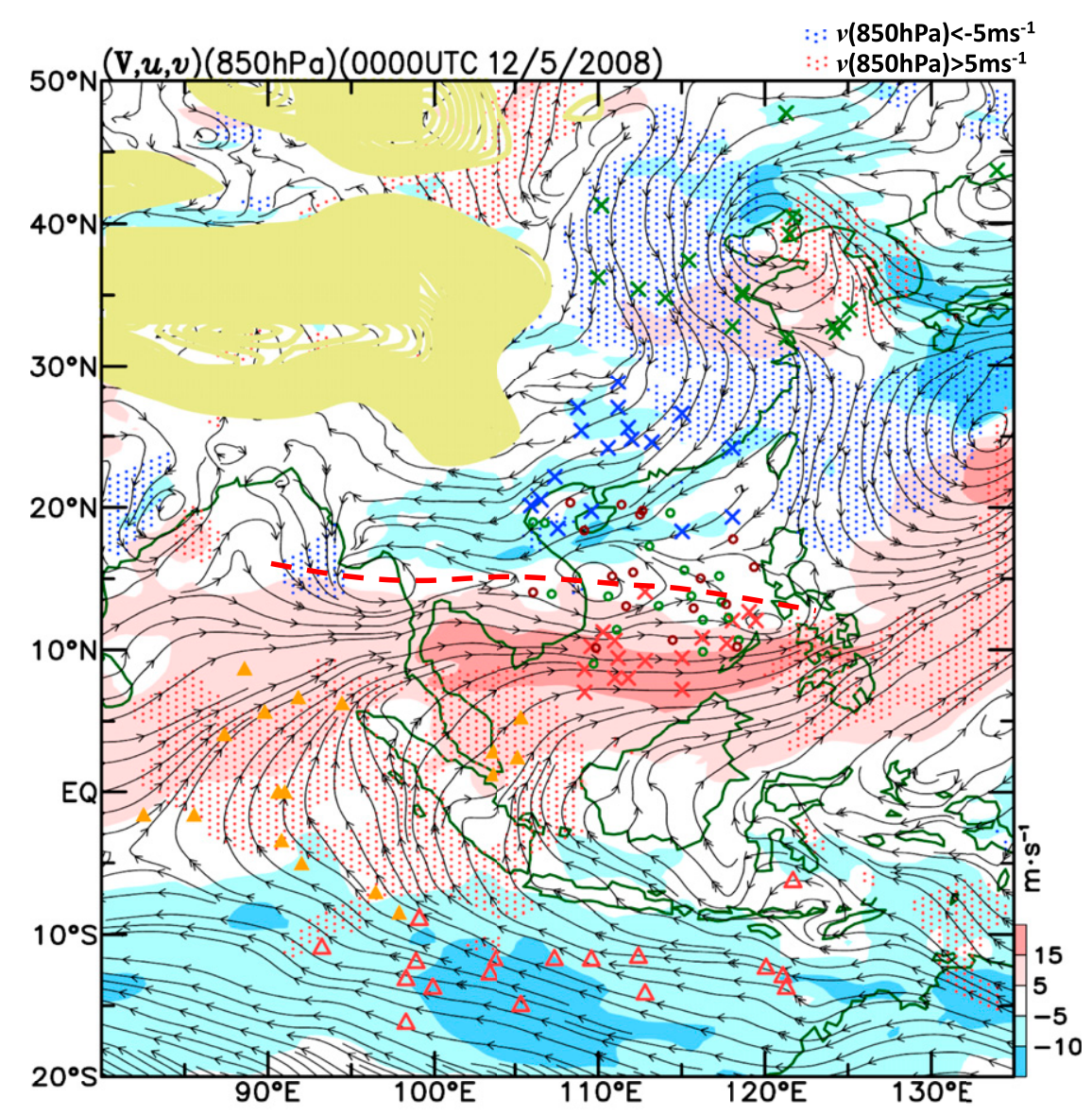

Locations at the maximum values of the following variable used to indicate the surge of the monsoon synoptic system

\begin{tabular}{|c|c|}
\hline$v_{\mathrm{NA}}(850 \mathrm{hPa})$ for cold surge-like flow & $\Delta \boldsymbol{u}_{\mathrm{ST}}(850 \mathrm{hPa})$ tropical easterly of the Southern \\
\hline & \\
\hline by $v_{\mathrm{CE}}$ & $\circ \zeta(850 \mathrm{hPa})$ associated with $\mathrm{TS} / \mathrm{TY}$ genesis \\
\hline${ }_{C E}(850 \mathrm{hPa})$ cross-equator flow from $\mathrm{SH}$ & $\circ-\omega(850 \mathrm{hPa})$ associated with $\mathrm{TS} / \mathrm{TY}$ genesis \\
\hline
\end{tabular}

FIG. 4. Locations at the maximum values of $u(850 \mathrm{hPa})$ and $v(850 \mathrm{hPa})$ for different components of the monsoon circulation are used to indicate the surge of the monsoon circulation materializing at the occurrence time of SCS TS/TY genesis. These locations are indicated by different color symbols show at the bottom of this figure. Time series of these variables are shown in Fig. 5. The 850-hPa streamline chart superimposed with velocity $(u, v)$ $(850 \mathrm{hPa})$ at 0000 UTC $5 \mathrm{Dec} 2008$, which is used as an example of a synoptic system to illustrate the synoptic conditions of TY Halong's genesis. The $850-\mathrm{hPa}$ wind components for $u(850 \mathrm{hPa})$ and $v(850 \mathrm{hPa})$ are colored and striped, respectively, by red and blue (westerly and easterly). The cyclonic shear line is indicated by a red dashed line.

only occurs under special conditions of the Southeast Asian monsoon circulation pattern. These special monsoon features/conditions are highlighted below.

a. Required environmental conditions for the occurrence of SCS TS/TY genesis in May

\section{1) MONSOON CIRCUlation}

1) The monsoon westerlies intensify and intrude eastward beyond $120^{\circ} \mathrm{E}$.
2) The maximum monsoon westerlies shift southward to latitudes south of $15^{\circ} \mathrm{N}$.

3) The monthly mean vorticity of the anomalous cyclonic shear flow in May $\Delta \zeta(850 \mathrm{hPa})$ should be $\geq 4 \times 10^{-6} \mathrm{~s}^{-1}$, when the monthly mean monsoon westerly flow in May meets conditions 1 and 2 .

4) The monsoon onset date over the SCS warm-season rainfall center west of the Philippines between $14^{\circ}$ and $16^{\circ} \mathrm{N}$ is 15 May. 

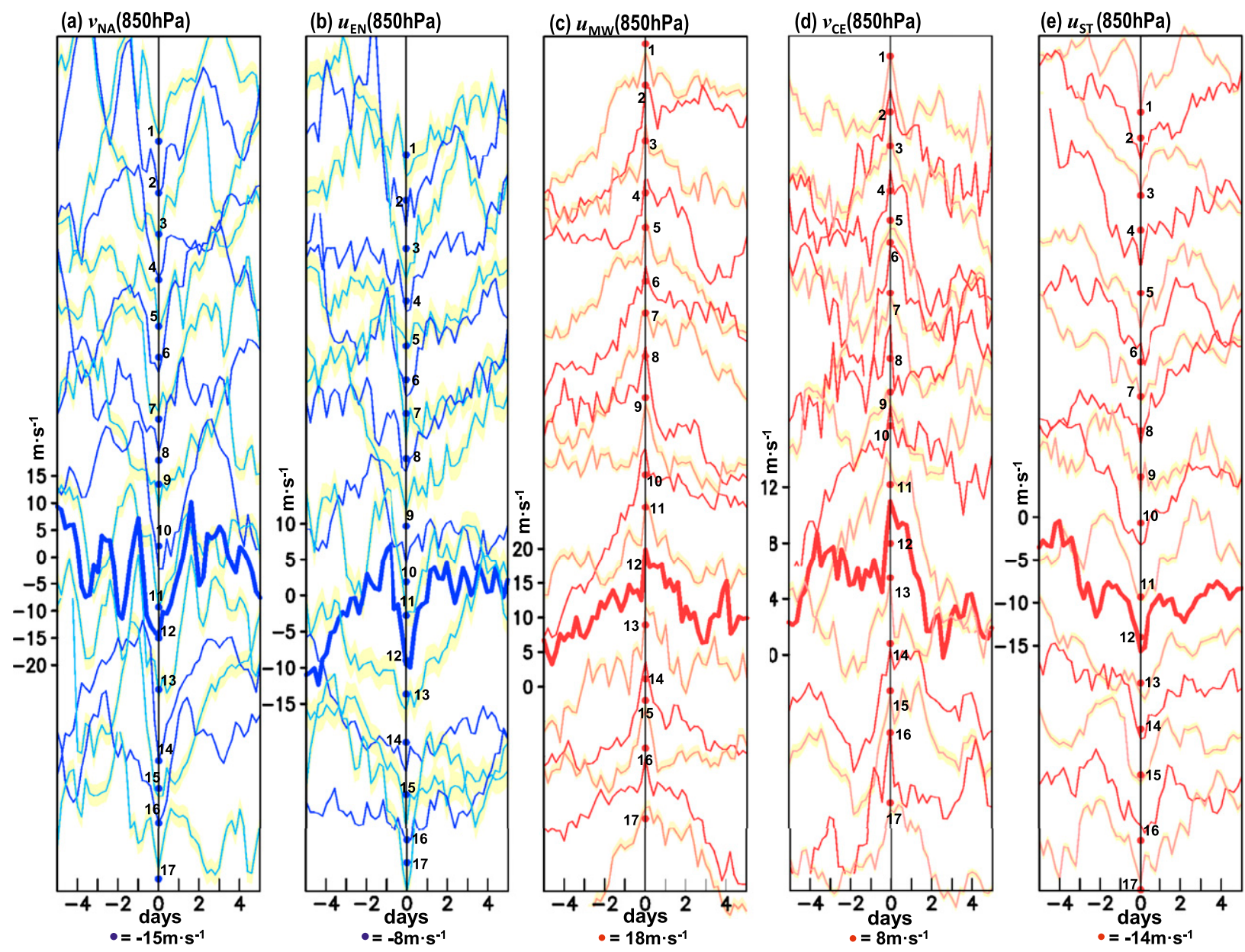

FIG. 5. Surges of the East-Southeast Asian monsoon circulation depicted by time series of the $850-\mathrm{hPa}$ zonal wind $u(850 \mathrm{hPa})$ and meridional wind $v(850 \mathrm{hPa})$ for five elements $\left(v_{\mathrm{NA}}, u_{\mathrm{EN}}, u_{\mathrm{MW}}, v_{\mathrm{CE}}, u_{\mathrm{ST}}\right)(850 \mathrm{hPa})$ of this monsoon circulation at locations marked in Fig. 4 at the genesis time of all 17 SCS TSs/TYs indicated by the order number displayed in Table 2. These monsoon surges are depicted with 11-day time series of $u(850 \mathrm{~Pa})$ and $v(850 \mathrm{hPa}), 5$ days prior to and after the genesis occurrence. The surges for all $u(850 \mathrm{hPa})$ and $v(850 \mathrm{hPa})$ time series are aligned along the $y$ axis on day 0 . The color of any variable's time series follows the colors of the variables shown in Fig. 4. The light yellow strip is alternatively added to the time series of this variable for every other TS/TY order number to help distinguish the time series of every TS/TY. Surge of the monsoon system embedded by the genesis of TY Halong (event 12) is used as an example, with time series of five wind components depicted with a thick line. The thick solid line is used to depict the time series of TY Halong (event 12) analyzed by Chen et al. (2010) as a sample to show the surge of a variable of interest. The scale added along the $y$ axis for any time series of TY Halong is also used to measure the magnitude of the variable shown by the time series of other TSs/TYs. The numerical order of every TS/TY genesis shown in Table 2 is added along the $y$ axis at day 0 . A black dot associated with this TS/TY is added along the $y$ axis to indicate the basic value (shown at the bottom of every panel) of a time series, so that the scale of TY Halong's time series can be used for the other 16 TSs/TYs.

\section{2) SYNOPTIC CONDITIONS}

1) An east-west-oriented cyclonic shear flow develops across the SCS, formed by the tropical easterlies that are fed by the northeast Asian cold-surge-like flow or the tropical easterlies of the western North Pacific anticyclone to the north and the intensified monsoon westerlies to the south of this shear flow.

2) The area-averaged vorticity of a TS/TY genesis vortex over the area with its $\zeta(850 \mathrm{hPa}) \geq 1.6 \times 10^{-5} \mathrm{~s}^{-1}$ can be intensified by more than $3.6 \times 10^{-5} \mathrm{~s}^{-1}$ in a day.

\section{3) TRIgGeRING MECHANISM OF SCS TS/TY GENESES: MONSOON SURGE}

1) Surges in both the tropical easterly flow and the monsoon westerlies forming the cyclonic shear flow across the SCS.

2) Surges in $(\zeta,-\omega)(850 \mathrm{hPa})$ emerge from these two variables averaged over the TS/TY genesis vortex over the area with threshold values of $\zeta(850 \mathrm{hPa}) \geq 2 \times$ $10^{-5} \mathrm{~s}^{-1}$ and $-\omega(850 \mathrm{hPa}) \geq 10^{-3} \mathrm{hPa} \mathrm{s}^{-1}$, respectively.

3) Surges also appear in the dynamic processes of the vorticity budget. 
(a) $\zeta(850 \mathrm{hPa})$

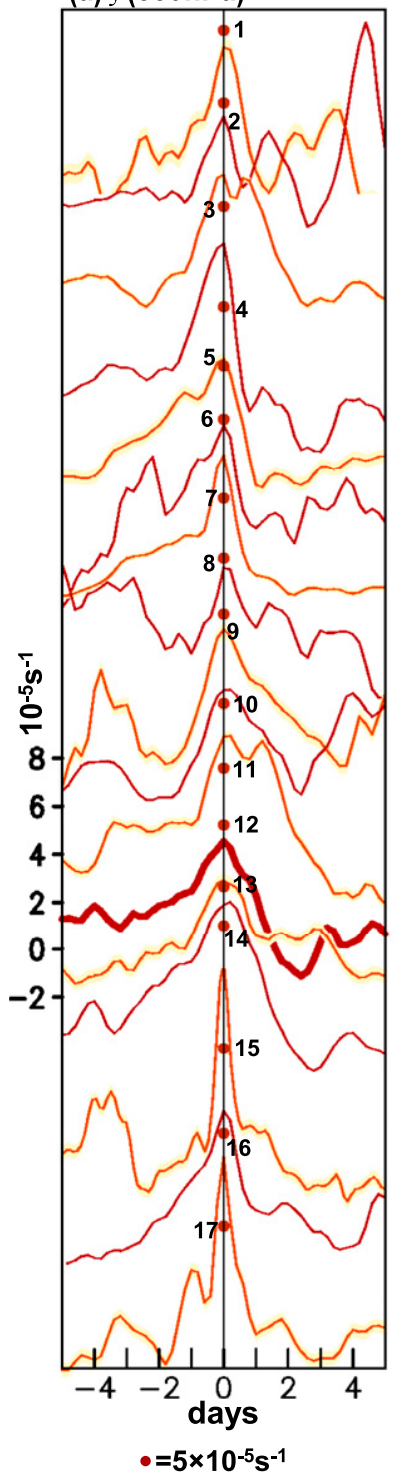

(b) $-\omega(850 \mathrm{hPa})$

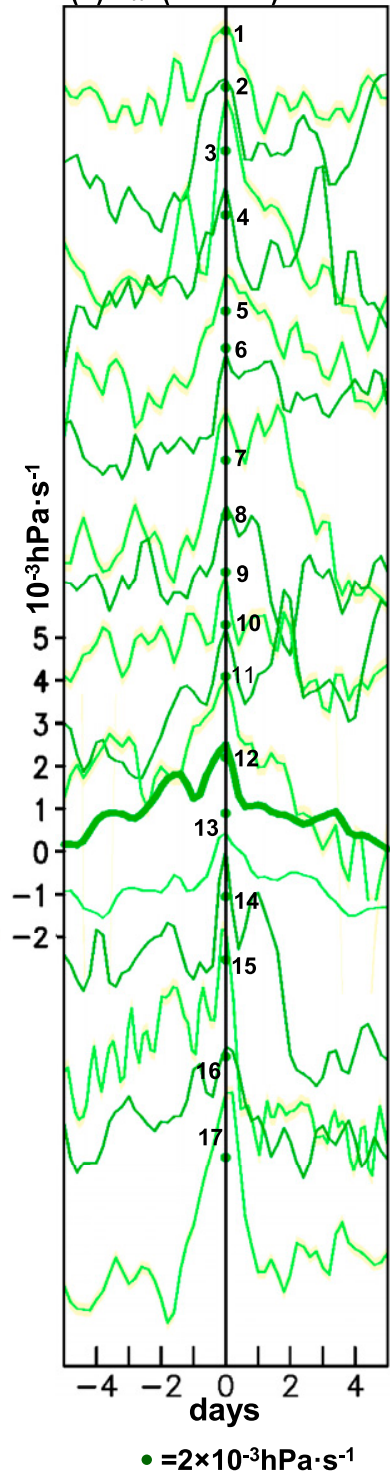

FIG. 6. As in Fig. 5, but for surges of $\zeta(850 \mathrm{hPa})$ and $-\omega(850 \mathrm{hPa})$ at the occurrence time of TS/TY genesis. Threshold values for the area average are $\zeta(850 \mathrm{hPa}) \geq 2 \times 10^{-5} \mathrm{~s}^{-1}$ and $-\omega(850 \mathrm{hPa}) \geq 10^{-3} \mathrm{hPa} \mathrm{s}^{-1}$.

Using specific features of the Southeast Asian monsoon circulation, synoptic conditions across the SCS, and the monsoon surge highlighted above, results obtained from the statistical analysis of the GFS forecasts for SCS TS/TY genesis are incorporated to develop a simple forecast advisory for the occurrence of SCS TS/TY genesis in May.

\section{b. Statistics of forecast}

\section{1) SOUTHEAST ASIAN MONSOON CIRCULATION IN MAY}

If the monthly mean forecast of the Southeast Asian monsoon circulation is operationally feasible and

accurate, the interannual variation of these monsoon westerlies in May, as shown in Fig. 1a, may offer a means of predicting the potential occurrence of SCS TS/TY genesis during this month. Revealed from our observations, even though the monthly mean circulation exhibits a strong monsoon circulation pattern in May, the monsoon westerlies may not appear every day south of $15^{\circ} \mathrm{N}$, as indicated by Fig. 10a. On the other hand, it is of interest to find that strong monsoon westerlies appear at least 5 days prior to the occurrence of SCS TS/TY genesis. Furthermore, the basic characteristics of the Southeast Asian monsoon circulation favorable for SCS TS/TY genesis shown in Fig. 1 are well depicted by this 5-daymean GFS-ERA-Interim reanalysis (presented in online supplement 7 to this paper). As long as the day 5 forecasts for GFS and GEFS show forecastability of the Southeast Asian monsoon westerlies during the month of May, we may use the GFS/GEFS 5-day forecasts to explore whether the global forecast model can provide the 5-day forecasts for the strong monsoon 5 days ahead of TS/TY genesis. To confirm this suggestion, the day 5 forecasts for the monsoon westerlies and the date of TS/TY genesis in May are shown in Fig. 10b. The 5-day average monsoon westerlies for day 5 forecasts at the latitude of the maximum westerlies (easterlies) south of $15^{\circ} \mathrm{N}$ are marked by a red TY symbol (green dot). A wide, red line marks day 5 forecasted $u(850 \mathrm{hPa}) 5$ days ahead of SCS TS/TY genesis, while a wide, green line denotes the easterlies 5 days ahead of SCS vortex formation. SCS vortex formation, marked by a blue, open triangle in Fig. 10b, is also possible when the monsoon flow is strong.

Shown in Fig. 11, some basic characteristics of the Southeast Asian monsoon circulation in May prepared with the 5-day forecasts for NCEP GFS and GEFS for the 1985-2016 period are highlighted below:

1) The $x-t$ diagram of $u(850 \mathrm{hPa})$ prepared with day 5 forecasted $u(850 \mathrm{hPa})$ averaged for 5 days ahead of the following three synoptic events: (i) the latitude of maximum westerlies is south of $15^{\circ} \mathrm{N}$ when TS/TY genesis and some SCS vortex formations occur, (ii) the latitude of maximum easterlies is south of $15^{\circ} \mathrm{N}$ when the SCS vortex forms, and (iii) the latitude of maximum easterlies appears during the last 5 days of May without any SCS vortex formation. SCS TS/TY genesis occurs, when the eastward intrusion of the 5-day averaged $u(850 \mathrm{hPa})$ prepared with day 5 forecasts is beyond $120^{\circ} \mathrm{E}$.

2) The maximum 5-day-averaged monsoon westerlies of day 5 forecasts are located south of $15^{\circ} \mathrm{N}$, when SCS TS/TY genesis occurs (Fig. 11b).

3) A cyclonic shear flow is formed across the SCS with day 5 forecasted $\mathbf{V}(850 \mathrm{hPa})$ averaged over 5 days 

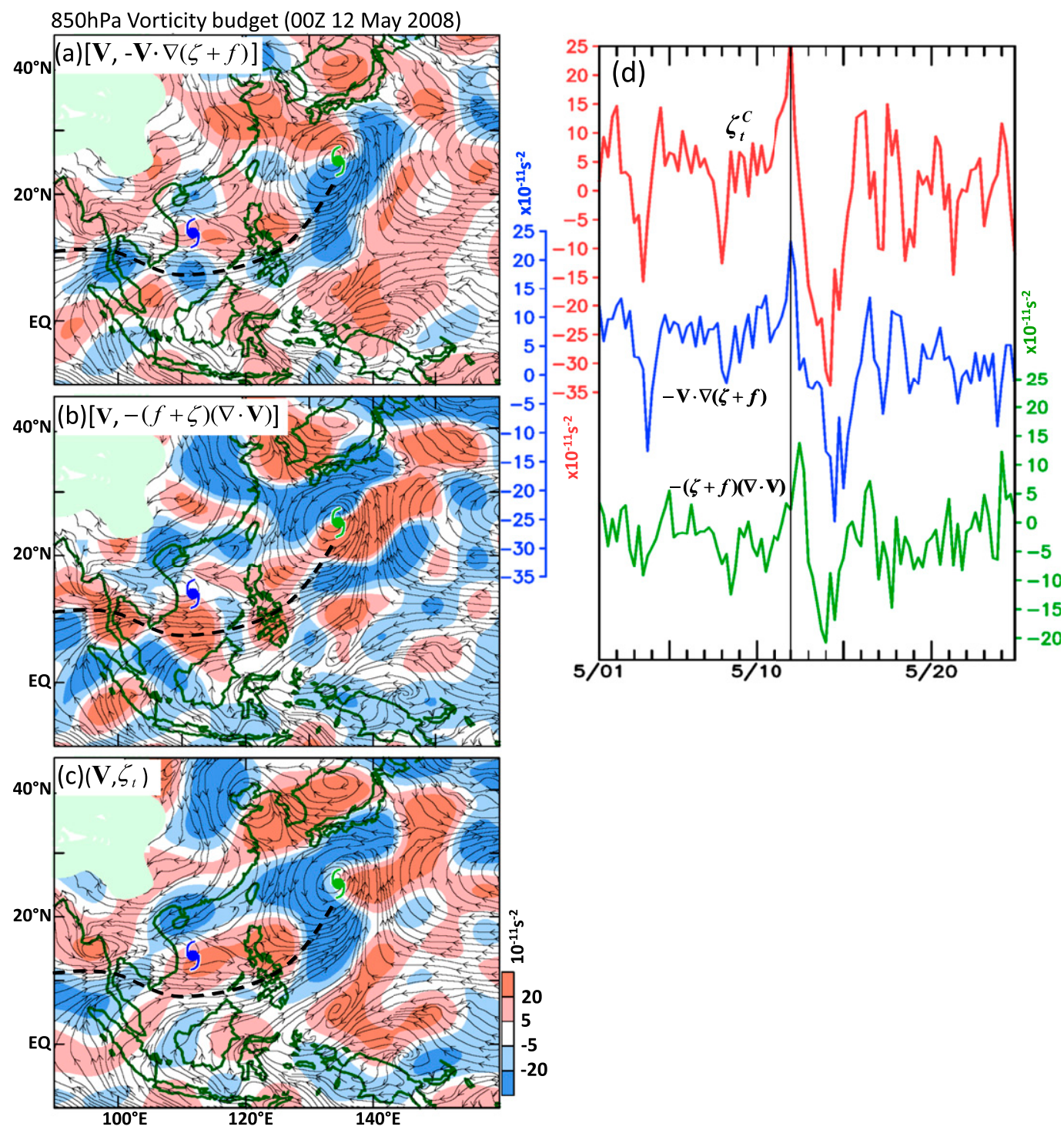

FIG. 7. The synoptic conditions at the genesis occurrence time (0000 UTC 12 May 2008) of TY Halong depicted by the $850-\mathrm{hPa}$ streamline charts superimposed with the $850-\mathrm{hPa}$ vorticity budget analysis: (a) the total vorticity advection $-\mathbf{V} \cdot(\zeta+f)$, (b) the vortex stretching $-(\zeta+f) \nabla \cdot \mathbf{V}$, (c) the vorticity tendency $\zeta_{t}$, and (d) time series for these three dynamic processes at the genesis location of TY Halong $\left(14^{\circ} \mathrm{N}, 112^{\circ} \mathrm{E}\right)$. This figure is condensed from Figs. 9 and 11 in Chen et al. (2010).

ahead of SCS TS/TY genesis. The vorticity center for this cyclonic shear flow averaged over a threshold value of $\Delta \zeta(850 \mathrm{hPa}) \geq 10^{-6} \mathrm{~s}^{-1}$ appears where SCS TS/TY genesis or the SCS vortex formation occurs (Fig. 11c).

The basic characteristics of the Southeast Asia monsoon circulation pattern depicted by the 5-daymean variables for day 5 forecasts resemble those prepared with the 5-day-mean reanalyses prior to SCS TS/TY genesis in May (shown in online supplement 6).

\section{2) SYNOPTIC CONDITIONS: FORECASTED SYNOPTIC CONDITIONS FOR SCS TS/TY GENESIS}

The development of SCS cyclonic shear flow establishes a favorable environment for SCS TS/TY genesis. As shown in Fig. 3, intensities for some SCS vortices formed in the cyclonic shear flow and some vortices generated from SCS TS/TY genesis may be comparable on day 0 . Nevertheless, the vortex intensity of the former group drops after day 0 , while that for the latter group is enhanced. On day 1 , vortex intensity of 


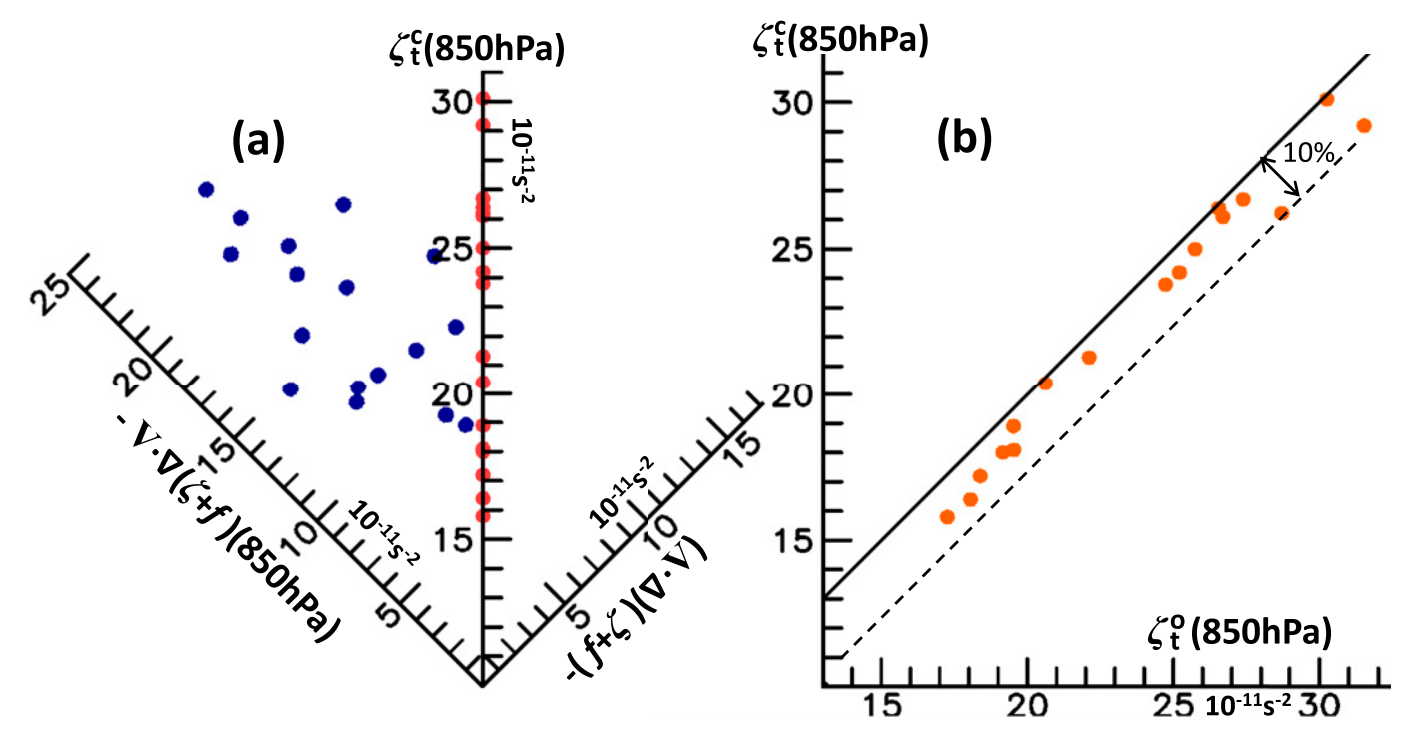

FIG. 8. (a) Scatter diagram of the 850 -hPa vorticity advection $-\mathbf{V} \cdot(\zeta+f)(850 \mathrm{hPa})$ and the 850 -hPa vorticity stretching $-(f+\zeta) \nabla \cdot \mathbf{V}(850 \mathrm{hPa})$ at the occurrence time of TS/TY genesis. The green dot is the vorticity tendency $\zeta_{t}^{C}(850 \mathrm{hPa})$ estimated by the combination of these two terms. (b) Scatter diagram of the 850-hPa vorticity tendency $\zeta_{t}^{o}(850 \mathrm{hPa})$ estimated directly from the $\zeta(850 \mathrm{hPa})$ derived from reanalysis data by a central finite-difference approach, and the vorticity tendency $\zeta_{t}^{C}(850 \mathrm{hPa})$ estimated by the vorticity budget equation. The boundary of the $10 \%$ error is indicated by the black, dashed line in parallel with the diagonal solid line.

the second group is distinctively larger than that of the first group.

It was shown in section $3 \mathrm{c}$ that SCS TS/TY genesis is a spinup process of the perturbation embedded in the cyclonic shear flow in response to surges of several crucial components of the monsoon circulation. This genesis is also reflected by the surge of $\zeta(850 \mathrm{hPa})$ averaged over the vortex of SCS TS/TY genesis [with a threshold value of $\left.\zeta(850 \mathrm{hPa}) \geq 1.6 \times 10^{-5} \mathrm{~s}^{-1}\right]$. Using this surge for $\zeta(850 \mathrm{hPa})$ as a criterion, the optimum forecast time for $13 \mathrm{SCS}$ TS/TY genesis events during 1985-2016 shown in Fig. 12a is 3 days. The formation of the SCS vortices within the cyclonic shear flow and the vortices of SCS TS/TY genesis forecasted with the optimum time of 3 days show some slight overlap in their intensities, but the intensities for both vortex groups are distinctly separated in the day 4 forecasts (Fig. 12b). Practically and operationally, this forecast approach is a feasible method for separating these two groups of vortices.

\section{3) TRIGGERING MECHANISM OF SCS TS/TY GENESIS}

The response of the SCS cyclonic shear to the monsoon surge is the spinup of a perturbation into its TS/TY genesis. This triggering mechanism of SCS TS/TY genesis is reflected by the time series of area-averaged $\zeta(850 \mathrm{hPa})$ over vortices of 17 identified SCS TS/TY geneses with a threshold value $\zeta(850 \mathrm{hPa}) \geq 1.6 \times 10^{-5} \mathrm{~s}^{-1}$ at their genesis locations shown in Fig. 6 a.

The time series of forecasted area-averaged $\zeta(850 \mathrm{hPa})$ at locations for these TS/TY geneses with a 3-day optimum forecast time merged with observed $\zeta(850 \mathrm{hPa})$ time series are shown in Fig. 13a. The scatter diagram of observed $\zeta(850 \mathrm{hPa})$ surge value versus forecasted $\zeta(850 \mathrm{hPa})$ surge value is shown in Fig. 13b. The least squares fit regression line generated by the two-tailed Student's $t$ test (Ott and Longnecker 2001) against the diagonal line shows that the difference between forecasted and observed surge values of $\zeta(850 \mathrm{hPa})$ is about $86 \%$. Regardless of this underforecasted $\zeta(850 \mathrm{hPa})$ surge value for SCS TS/TY genesis, the statistics for SCS TS/TY genesis presented in this section provide a base for developing a forecast advisory for SCS TS/TY genesis using both GFS and GEFS forecasts at least 3 days ahead of the announcement/warning of the TS/TY genesis in May.

\section{c. Illustration of the forecast advisory for SCS TS/TY genesis in May}

Statistical analyses of three requirements for the occurrence of SCS TS/TY genesis during May were performed with the GFS (2004-16) and GEFS (1985-2003) forecasts in section $4 \mathrm{~b}$. Based on results from these statistical analyses, a forecast advisory for SCS TS/TY genesis in May is presented in Fig. 14. This forecast advisory contains the following four steps: 

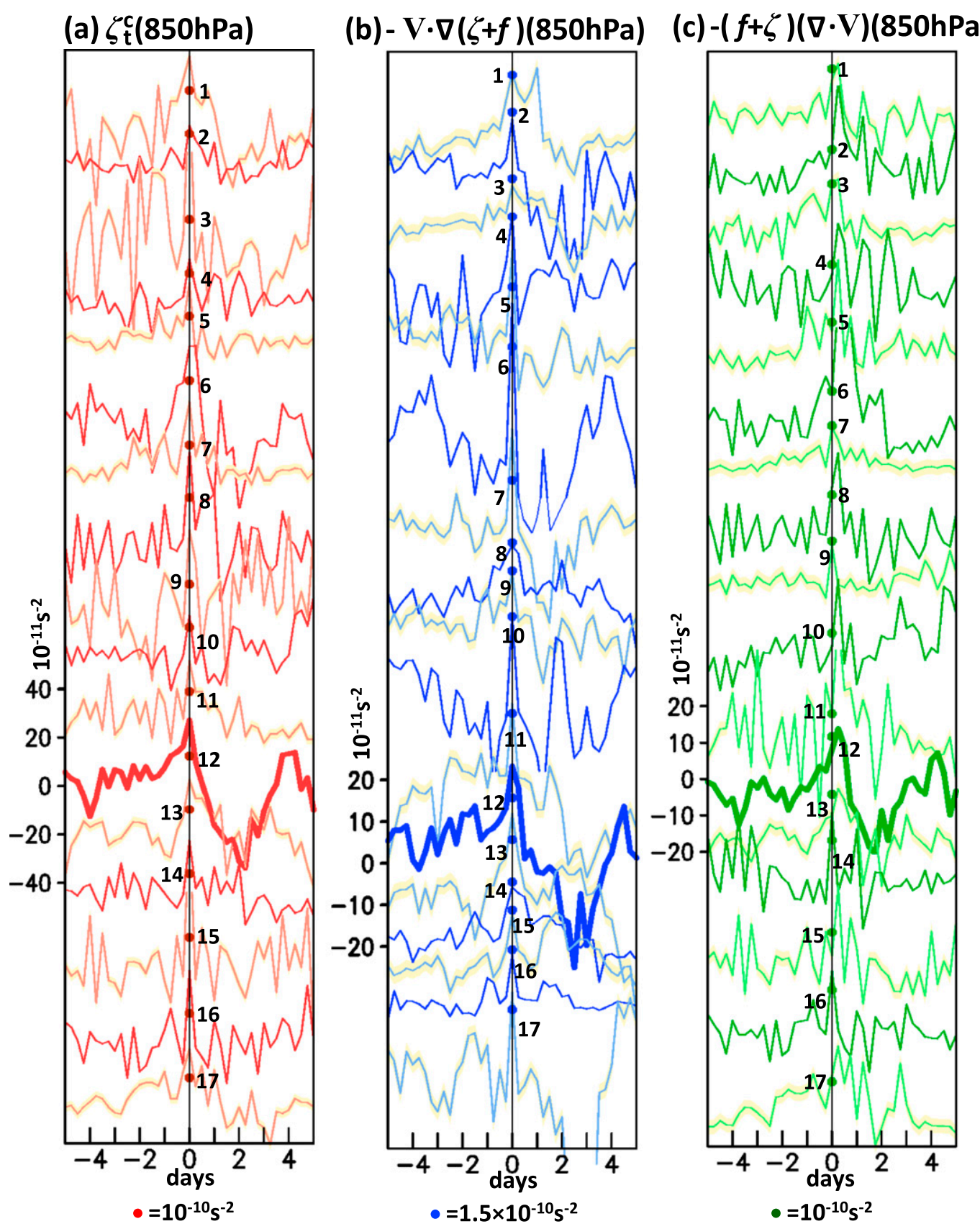

FIG. 9. As in Fig. 7b, but for time series of three dynamic processes: (a) vorticity tendency estimation by the vorticity equation, (b) vorticity advection, and (c) vortex stretching. Colors of time series for these three variables are the same as those shown in Fig. 7b. Yellow strips are added on the times series of the three variables as in Figs. 5 and 6.

1) Step 1-Determine whether favorable circulation conditions of the Southeast Asian monsoon in May depicted by the 5-day average of day 5 forecasts meet the following conditions:

The 5-day average of day 5 forecasts against the corresponding long-term 5-day average at day 5 forecasts for the same time period is used to determine whether the monsoon westerlies are intensified. If the outcome is positive, the following three criteria must be met:

(i) the eastward intrusion of monsoon westerlies exceeds $120^{\circ} \mathrm{E}$,

(ii) the maximum monsoon westerlies are located south of $15^{\circ} \mathrm{N}$, and 


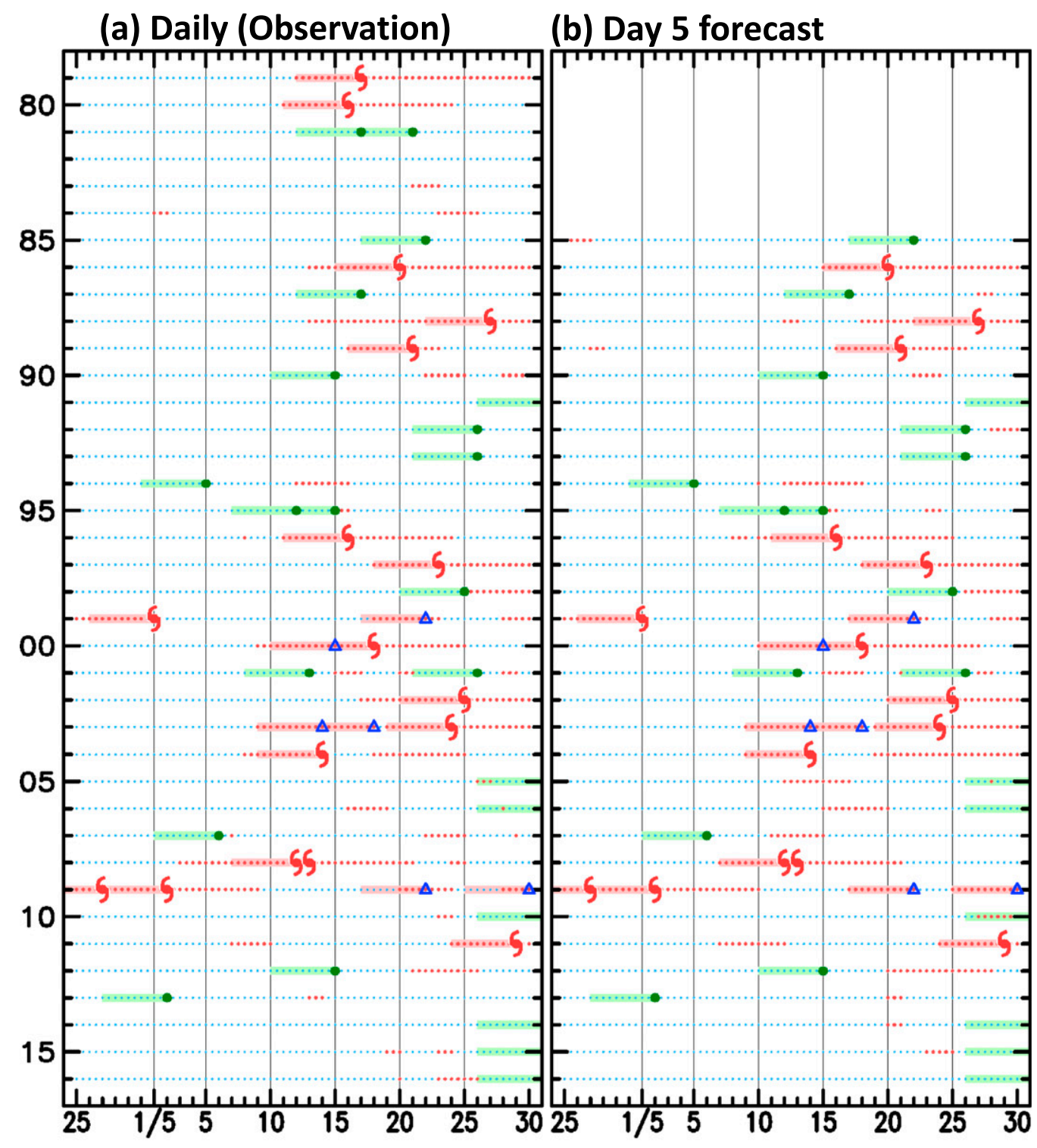

Observed daily monsoon westerly maximum exists south of $15^{\circ} \mathrm{N}$, and the monsoon westerlies intrude eastward beyond $120^{\circ} \mathrm{E}$.

Observed daily easterly maximum exists in south of $15^{\circ} \mathrm{N}$ in the SCS.

Daily monsoon westerly maximum of Day 5 forecast exists south of $15^{\circ} \mathrm{N}$, and the monsoon westerlies intrude eastward beyond $120^{\circ} \mathrm{E}$.

Daily easterly max of Day 5 forecast exists in south of $15^{\circ} \mathrm{N}$ in the SCS.

TS/TC formed in SCS and - SCS vortex formed with weak move northeastward monsoon westeries in May $\triangle$ SCS vortex formed with strong monsoon westerlies in May

FIG. 10. (a) The observed daily SCS maximum monsoon westerly flow is located south of $15^{\circ} \mathrm{N}$. Shown is the eastward intrusion of this monsoon flow beyond $120^{\circ} \mathrm{E}$. A red dot indicates the monsoon conditions. The occurrence time of SCS TS/TY genesis is marked by a red typhoon symbol. A red strip is added when TS/TY genesis occurs after the appearance of 5-day persistent monsoon westerlies. Under these strong monsoon conditions, an SCS vortex may form. A blue, open triangle is marked at the formation time of this vortex. When the observed daily easterly maximum appears south of $15^{\circ} \mathrm{N}$ and extends westward beyond $120^{\circ} \mathrm{E}$, a blue dot is marked. If a SCS vortex forms under these weak monsoon conditions, the SCS vortex may form, and its formation time is marked by a larger green dot. A green strip is added 5 days ahead of the SCS vortex formation. (b) As in (a), but here the monsoon westerlies and easterlies use day 5 forecasts for GFS for 2004-16 and for GEFS for 1985-2003. 


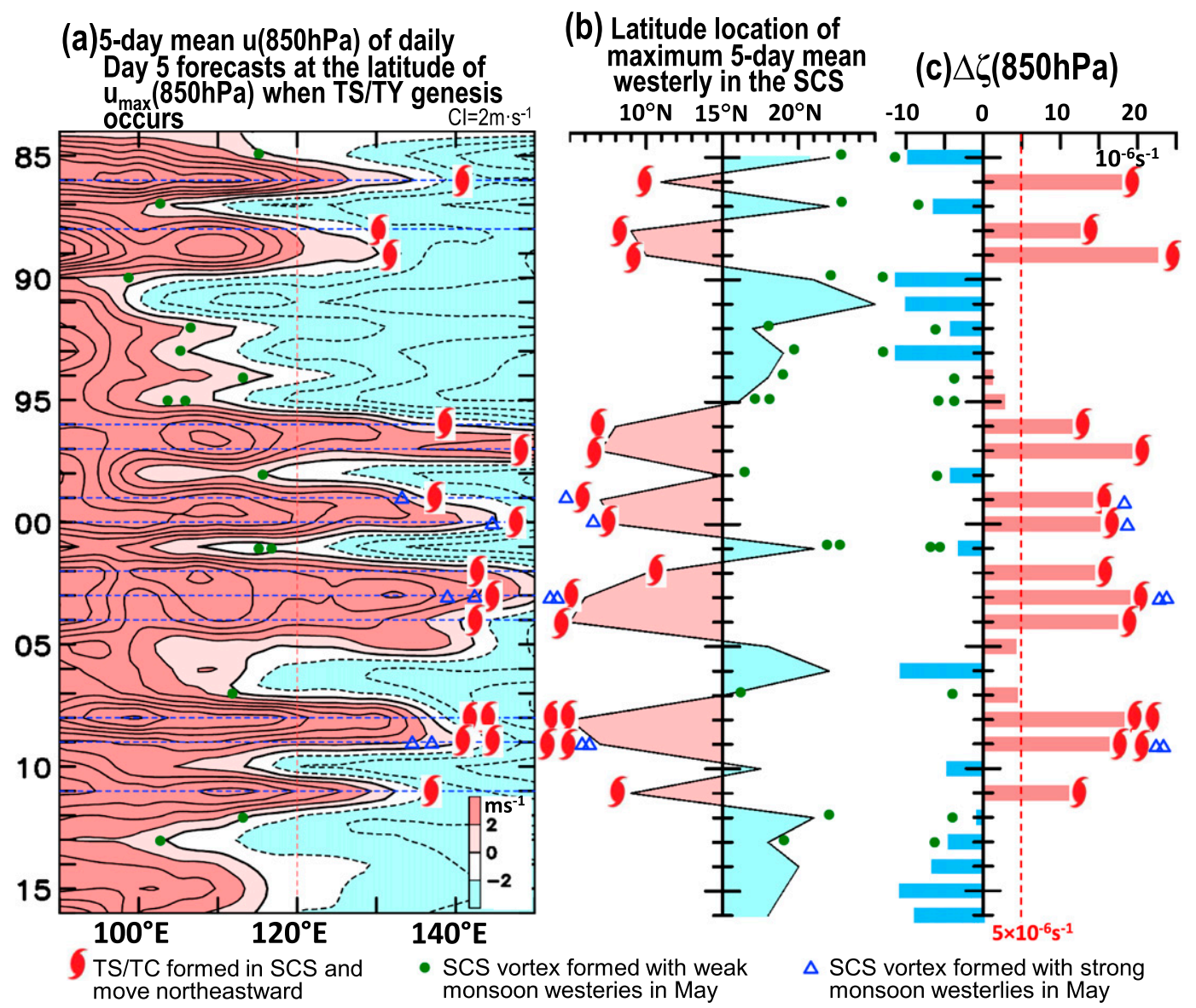

FIG. 11. (a) The $x$ - $t$ diagram of 5-day-mean 850 -hPa monsoon westerly flow with the day 5 forecasts. Time period is 5 days prior to TS/TY genesis or the SCS vortex. The latitudinal location of the maximum monsoon westerly or easterly is south of $15^{\circ} \mathrm{N}$. (b) Latitude of the maximum 5-day-mean forecasted 850-hPa westerlies of day 5 forecasts before TS/TY genesis of vortex formation. (c) The area average of the $\Delta \zeta(850 \mathrm{hPa})$ anomaly over either the maximum or minimum $\Delta \zeta(850 \mathrm{hPa})$ center surrounded by a threshold value $|\Delta \zeta(850 \mathrm{hPa})| \geq 10^{-6} \mathrm{~s}^{-1}$ in the SCS region $\left(10^{\circ} \sim 20^{\circ} \mathrm{N}, 110^{\circ} \sim 120^{\circ} \mathrm{E}\right)$. The TS/TY geneses and formations of SCS vortices in the SCS are marked by red typhoon symbols and green dots, respectively. The monsoon vortices formed in the strong monsoon westerlies during May are denoted by open, blue triangles.

(iii) the area-average $\Delta \zeta(850 \mathrm{hPa})$ over the area with a threshold value $\geq 10^{-6} \mathrm{~s}^{-1}$ located in the cyclone shear flow north of the monsoon westerlies should be $\geq 14 \times 10^{-6} \mathrm{~s}^{-1} \sigma(\sigma=$ $2.6 \times 10^{-6} \mathrm{~s}^{-1}$, standard deviation).

2) Step 2-Examine whether the SCS synoptic cyclonic shear flow appears in the day 5 forecast of the selected 5-day forecast flow; a favorable synoptic environment for the occurrence of SCS TS/TY genesis is established by this cyclonic shear flow. If this SCS cyclonic shear flow exists, two criteria should be satisfied by these forecasts:

(i) the optimum forecast time of SCS TS/TY genesis is 3 days and

(ii) there is significant intensification of the TS/TY genesis vortex on the day 5 forecast in comparison with the SCS vortex.
3) Step 3-Test the spinup process (triggering mechanism) of SCS TS/TY genesis at its genesis location through the hybrid $\zeta(850 \mathrm{hPa})$ time series with the observed results and the 3-day forecast. The surge of the forecasted $\zeta(850 \mathrm{hPa})$ should be $\sim 86 \%$ of the observed result, averaged over the area with a threshold value of $\zeta(850 \mathrm{hPa}) \geq 2 \times 10^{-5} \mathrm{~s}^{-1}$.

4) Step 4-Issue a warning of SCS TS/TY genesis 3 days ahead of its occurrence.

Developed from the statistical analysis for the GFS and GEFS forecasts over the period of 1985-2016, this forecast advisory should be feasible. Nevertheless, based on the $x-t$ diagram of the monthly mean $u(850 \mathrm{hPa})$ shown in Fig. 1, it is likely the monsoon westerlies in Southeast Asia may be intensified in the next 1-2 yr after 2016. The feasibility of this forecast advisory can be further confirmed. 


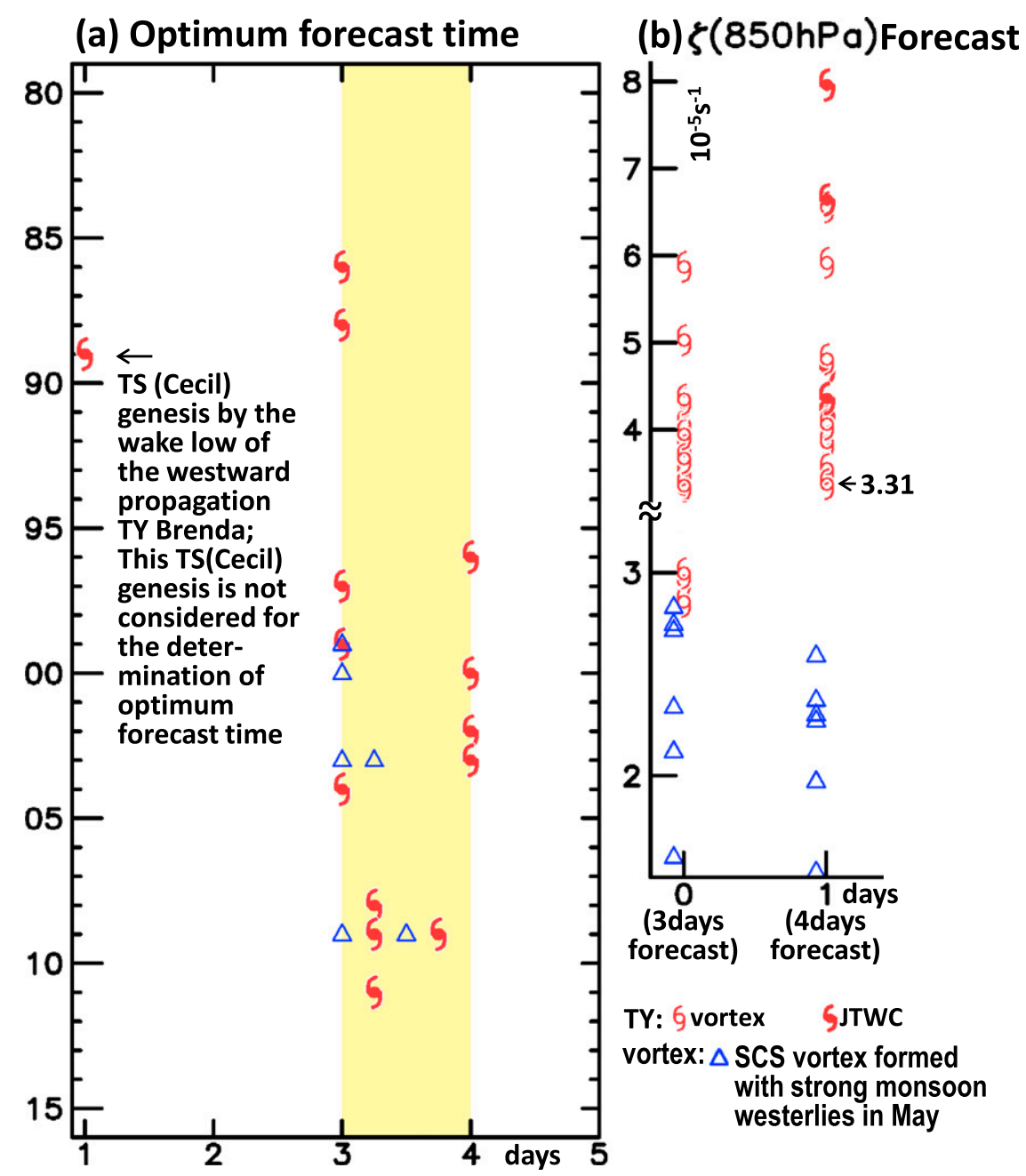

FIG. 12. (a) Optimum forecast time for SCS TS/TY genesis and vortex formation when monsoon westerlies are strong. (b) Intensity of TS/TY genesis vortex and monsoon vortex formation at the 3 -day optimum forecast time and 1 day beyond the optimum forecast time.

\section{Concluding remarks}

May is the transition month in East-Southeast Asia from the cold-season northwesterly monsoon to the warm-season southwesterly monsoon on the onset date of the later monsoon. Previous studies (e.g., Lau and Yang 1997; Zhou and Chan 2007) showed the onset date is moving earlier, when the monsoon westerlies are significantly intensifying. In addition to the impact on this monsoon transition, it is observed in the present study that SCS TS/TY genesis only occurs during May when the monsoon westerlies intensify. This intensification of the SCS monsoon westerlies is accompanied by a deepening of the SCS monsoon trough, which is reflected by the development of a monthly mean anomalous cyclonic shear flow around the Asian continent. This anomalous cyclonic shear flow facilitates the development of the east-west-oriented synoptic-scale cyclonic shear flow across the SCS, which provides a favorable environment for SCS TS/TY genesis. A synoptic perturbation embedded in this shear flow can be spun up by surges in the monsoon circulation.

Three salient features can characterize the favorable environment developed by the intensified Southeast Asian monsoon circulation in May for the 17 SCS TS/TY geneses over the period 1979-2016:

1) The SCS monsoon trough intensifies. The intensification of this trough is reflected by anomalous cyclonic shear flow around the Asian continent and the intensification of monsoon westerlies characterized by the following features:

(i) the eastward intrusion of monsoon westerlies moves beyond $120^{\circ} \mathrm{E}$, 


\section{(a) $\zeta(850 \mathrm{hPa})$}

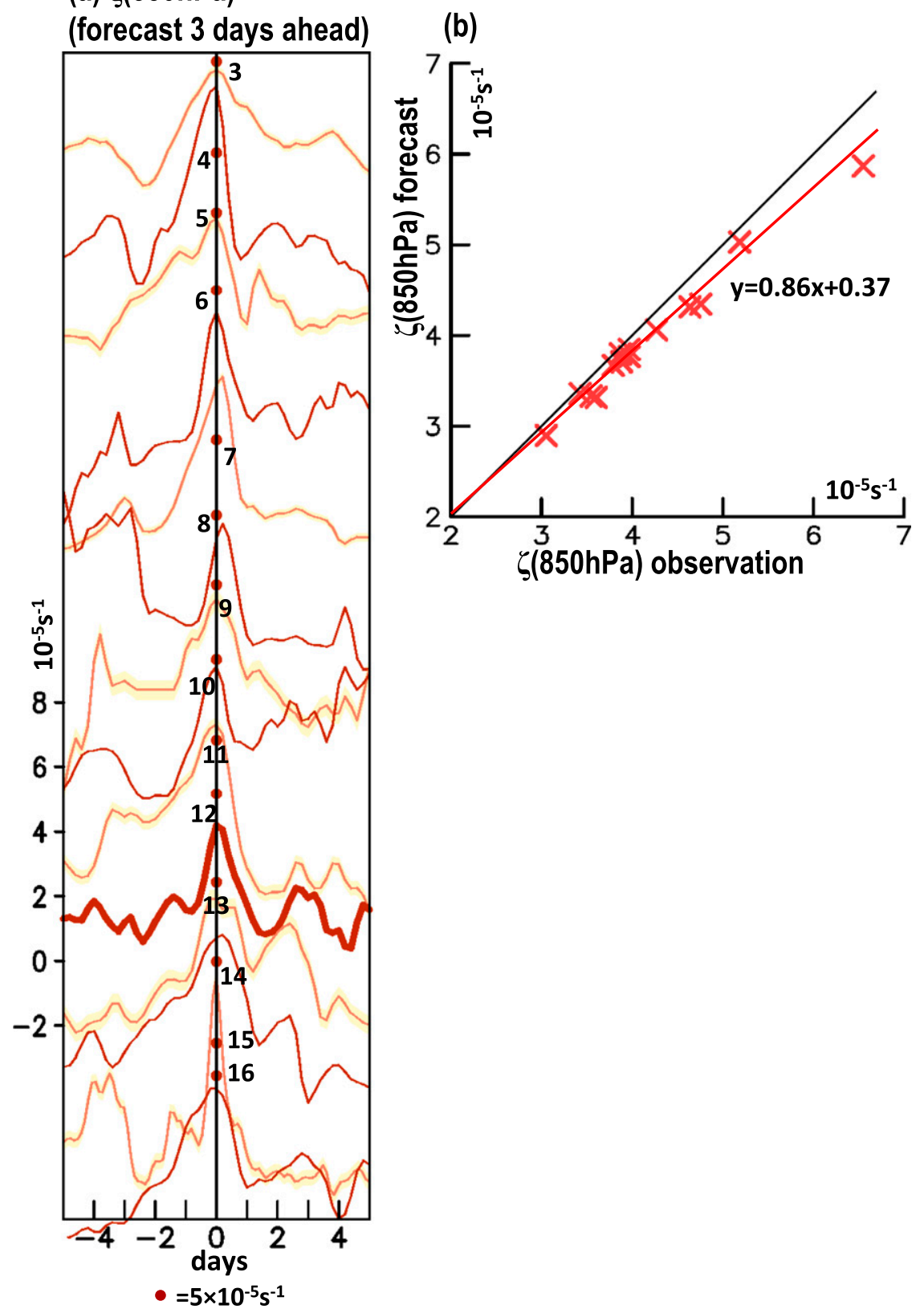

FIG. 13. (a) As in Fig. 6a, but for the 3-day forecasts ahead of TS/TY genesis. (b) A scatter diagram for the observational intensity of the TS/TY genesis vortex vs the day 3 forecast intensity of the TS/TY genesis at the time of formation.

(ii) the maximum westerlies are located south of $15^{\circ} \mathrm{N}$, and

(iii) $\Delta \zeta(850 \mathrm{hPa})$ at the $\zeta(850 \mathrm{hPa})$ center over the cyclonic shear flow exceeds $4 \times 10^{-6} \mathrm{~s}^{-1}$ when the monthly mean monsoon westerly flow meets conditions 1 and 2 .

2) Synoptic-scale cyclonic shear flow across the SCS is formed by the tropical easterly flow fed by the northeast Asian cold-surge flow from the north and the monsoon westerlies in the south.

The $\zeta(850 \mathrm{hPa})$ center for typical TS/TY genesis and the formation of an SCS vortex with strong monsoon westerlies on day 0 may be comparable $\left(\geq 1.6 \times 10^{-5} \mathrm{~s}^{-1}\right)$, but the intensity of the TS/TY group on day 1 becomes $\geq 3.6 \times 10^{-5} \mathrm{~s}^{-1}$, while the intensity of the typical vortex will be reduced 


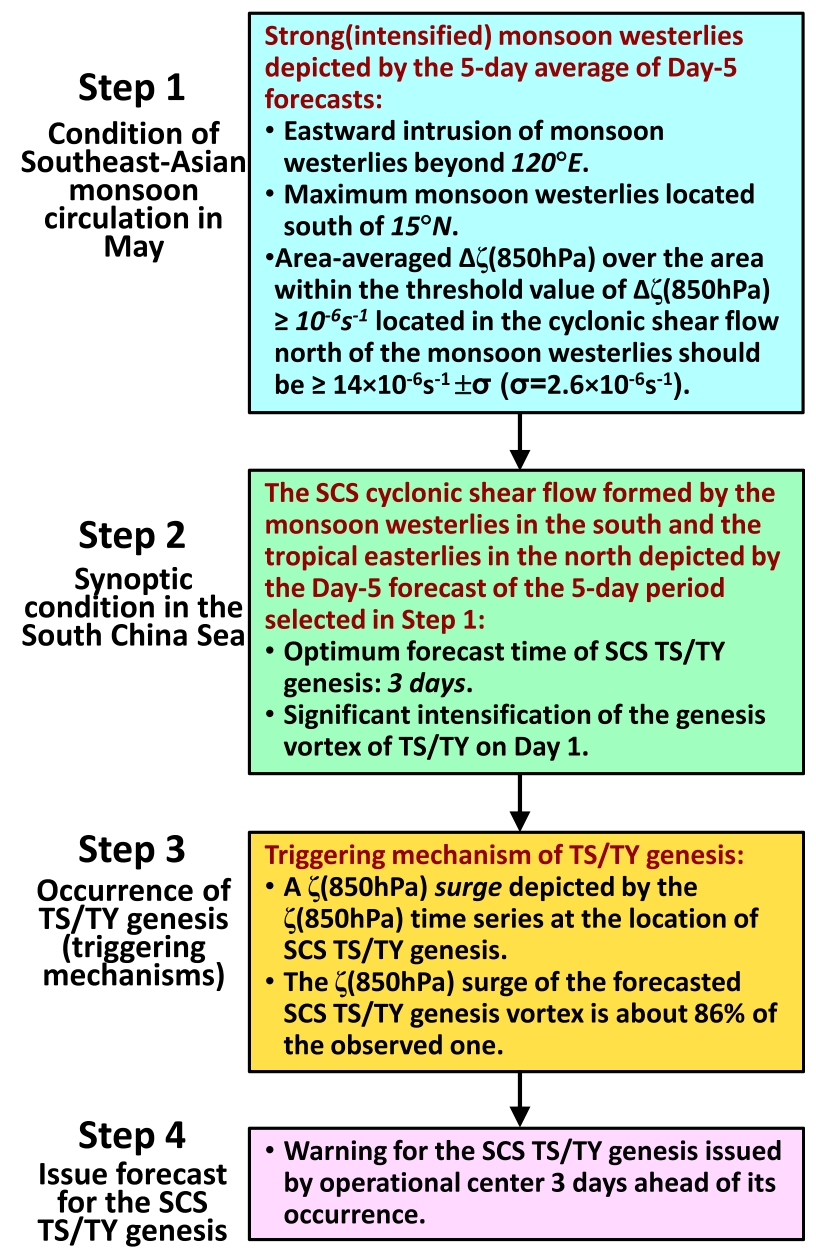

FIG. 14. Flowchart for the forecast advisory of SCS TS/TY genesis during May.

to $<3.2 \times 10^{-5} \mathrm{~s}^{-1}$. This disparity of vortex intensification provides a means of separating these two vortex groups.

3) Trigger mechanism of SCS TS/TY genesis-monsoon surge. This Southeast Asian monsoon surge is depicted by surges of $u(850 \mathrm{hPa})$ at the locations of maximum tropical easterlies north of the synoptic cyclonic shear flow, and at maximum monsoon westerlies south of this shear flow. The impact of this monsoon surge triggers SCS TS/TY genesis. This trigger mechanism is registered by surges in the following variables and dynamic processes:

(i) $(\zeta,-\omega)(850 \mathrm{hPa})$ averaged over the TS/TY genesis vortex with a threshold value $\geq 1.6 \times 10^{-5} \mathrm{~s}^{-1}$ and

(ii) dynamic processes included in the vorticity budget.

The special conditions for SCS TS/TY genesis include a deepening of the SCS monsoon trough, development of the synoptic-scale cyclonic shear flow in the SCS, and a surge of monsoon circulation observed in this study. Nevertheless, the most basic indicator for the occurrence of SCS TS/TY genesis in May is the strong monsoon westerlies. This is a unique set of environmental conditions for SCS TS/TY genesis during May. So far, operational centers still cannot provide skillful forecasts 1 month prior. This study observed that SCS TS/TY genesis occurs after the existence of strong monsoon westerlies over a 5-day period. The high-resolution $\left(0.5^{\circ} \times 0.5^{\circ}\right)$ extended $(8$ day) forecasts issued by the NCEP GFS (2004-16) and GEFS (1985-2003) are used to perform the statistical analysis of 15 SCS TS/TY geneses occurring in May:

1) Deepening of the SCS monsoon trough, intensification of monsoon westerlies, eastward intrusion of the intensified monsoon westerlies beyond $120^{\circ} \mathrm{E}$, and southward shift of the maximum monsoon westerly south of $15^{\circ} \mathrm{N}$ are well reflected by the 5-day average of day 5 forecasts ahead of the occurrence of an SCS TS/TY genesis event.

2) The synoptic-scale cyclonic shear flow across the SCS favorable for SCS TS/TY genesis is well depicted by the day 5 forecast for the genesis occurrences. We also find the optimum forecast time for the TS/TY genesis is 3 days. The intensity of TS/TY genesis and the SCS vortex during the strong Southeast Asian monsoon have some overlap on day 0 , but the intensity of the TS/TY genesis vortex becomes distinctly larger than the SCS vortex on day 1.

3) The spinup process for monsoon perturbation into the TS/TY genesis is well indicated by the surge of the $\zeta(850 \mathrm{hPa})$ time series at the location of TS/TY genesis with the 3 -day optimum forecast time merged with the observed $\zeta(850 \mathrm{hPa})$ time series.

The statistical-dynamic approach was utilized to provide the probabilistic forecasts for TS/TY genesis in the western North Pacific (e.g., Schumacher et al. 2009) and the tropical East Pacific and the Atlantic basin (e.g., Halperin et al. 2017). This approach may not be practical for providing operational forecasts for SCS TS/TY genesis in May. Based on statistical analyses of GFS/GEFS forecasts, a four-step forecast advisory for SCS TS/TY genesis is proposed:

1) strong (intensified) monsoon westerlies depicted by the 5-day average of day 5 forecasts,

2) the SCS synoptic-scale cyclonic shear flow formed by the monsoon westerlies in the south and the tropical easterlies in the north depicted by the day 5 forecast of the 5-day period selected in step 1 ,

3) a triggering mechanism for TS/TY genesis-monsoon surge, and

4) warning of SCS TS/TY genesis issued by operational center 3 days ahead of occurrence. 
In view of our endeavors for this study, more efforts are suggested to make the forecasting of SCS TS/TY genesis 1 month prior possible:

1) Because the impact of the Southeast Asian monsoon westerlies on SCS TS/TY genesis during May shown in Fig. 1 is asserted in terms of the monthly mean monsoon flow at $850 \mathrm{hPa}$, we hope that monthly mean forecasts will become feasible and skillful. We will then have a more legitimate forecast advisory tool for predicting SCS TS/TY genesis in May 1 month prior.

2) Previous studies (e.g., Lau and Yang 1997; Zhou and Chan 2007) demonstrated the coincident occurrence between the ENSO cycle and the intensification/ weakening of the SCS monsoon related to its monsoon onset. We have observed in the present study that the interannual variation of the SCS monsoon onset date is coincident with the interannual variation of the Southeast Asian monsoon intensity. Some discrepancy between the ENSO cycle and the interannual variation of the Southeast Asian monsoon circulation deserves further in-depth analysis.

3) Our preliminary analysis suggests the Southeast Asian monsoon surge may be caused by the constructive interference of the 30-60-, 12-24-, 8-12-, and 3-8-day monsoon modes. More in-depth analyses and numerical experiments are needed.

Acknowledgments. The Cheney Research Fund and NSF Grant ATM-0136220 sponsored this study. JM's contribution to this study is supported by JSPSKAKENHI Grant 26220202, and the Grand-in-Aid for Research on Priority and the Leading Project of Tokyo Metropolitan University, Japan. Comments/suggestions offered by anonymous reviewers were very helpful in improving the presentation of this manuscript.

\section{REFERENCES}

Ananthakrishnan, R., and M. K. Soman, 1988: The onset of the southwest monsoon over Kerala: 1901-1980. J. Climatol., 8, 283-296, doi:10.1002/joc.3370080305.

Chen, G., 2011: How does shifting Pacific Ocean warming modulate on tropical cyclone frequency over the South China Sea? J. Climate, 24, 4695-4700, doi:10.1175/2011JCLI4140.1.

Chen, T.-C., and J.-M. Chen, 1995: An observation study of the South China Sea monsoon during the 1979 summer: Onset and life cycle. Mon. Wea. Rev., 123, 2295-2318, doi:10.1175/ 1520-0493(1995)123<2295:AOSOTS > 2.0.CO;2.

, S.-Y. Wang, W.-R. Huang, and M.-C. Yen, 2004a: Variation of the East Asian summer monsoon rainfall. J. Climate, 17, 744-762, doi:10.1175/1520-0442(2004)017<0744:VOTEAS > 2.0.CO;2.

,,- M.-C. Yen, and W. A. Gallus Jr., 2004b: Role of the monsoon gyre in the interannual variation of tropical cyclone formation over the western North Pacific. Wea. Forecasting, 19, 776-785, doi:10.1175/1520-0434(2004)019<0776:ROTMGI >2.0.CO;2.
_ J.-D. Tsay, M.-C. Yen, and E. O. Cayanan, 2010: Formation of the Philippine twin tropical cyclones during the 2008 summer monsoon onset. Wea. Forecasting, 25, 1317-1341, doi:10.1175/2010WAF2222395.1.

Chen, X., Y. Wang, and K. Zhao, 2015: Synoptic flow patterns and large-scale characteristics associated with rapidly intensifying tropical cyclones in the South China Sea. Mon. Wea. Rev., 143, 64-87, doi:10.1175/MWR-D-13-00338.1.

Cossuth, J. H., R. D. Knabb, D. P. Brown, and R. E. Hart, 2013 Tropical cyclone formation guidance using pregenesis Dvorak climatology. Part I: Operational forecasting and predictive potential. Wea. Forecasting, 28, 100-118, doi:10.1175/ WAF-D-12-00073.1.

Dee, D. P., and Coauthors, 2011: The ERA-Interim reanalysis: Configuration and performance of the data assimilation system. Quart. J. Roy. Meteor. Soc., 137, 553-597, doi:10.1002/ qj. 828 .

Goh, A. Z.-C., and J. C.-L. Chan, 2009: Interannual and interdecadal variations of tropical cyclone activity in the South China Sea. Int. J. Climatol., 30, 827-843, doi:10.1002/joc.1943.

Gray, W. M., 1998: The formation of tropical cyclones. Meteor. Atmos. Phys., 67, 37-69, doi:10.1007/BF01277501.

Halperin, D. J., R. E. Hart, H. E. Fuelberg, and J. H. Cossuth, 2017: The development and evaluation of a statistical-dynamical tropical cyclone genesis guidance tool. Wea. Forecasting, 32, 27-46, doi:10.1175/WAF-D-16-0072.1.

Hamill, T. M., G. T. Bates, J. S. Whitaker, D. R. Murray, M. Fiorino, T. J. Galarneau, Y. Zhu, and W. Lapenta, 2013: NOAA's second-generation global medium range ensemble forecast dataset. Bull. Amer. Meteor. Soc., 94, 1553-1565, doi:10.1175/BAMS-D-12-00014.1.

- J. S. Whitaker, D. R. Murray, M. Fiorino, and T. J. Galarneau, 2016: A description of the 2nd-generation NOAA global ensemble reforecast data set. NOAA/ESRL, $10 \mathrm{pp}$. [Available online at http://www.esrl.noaa.gov/psd/forecasts/ reforecast2/README.GEFS_Reforecast2.pdf.]

JTWC, 2016: JTWC Tropical Cyclone Best Track Data Site. Joint Typhoon Warning Center. [Available online at http://www usno.navy.mil/NOOC/nmfc-ph/RSS/jtwc/best_tracks/.]

Kajikawa, Y., and B. Wang, 2012: Interdecadal change of the South China Sea summer monsoon onset. J. Climate, 25, 3207-3218, doi:10.1175/JCLI-D-11-00207.1.

Lau, K.-M., and S. Yang, 1997: Climatology and interannual variability of the Southeast Asian summer monsoon. Adv. Atmos. Sci., 14, 141-162, doi:10.1007/s00376-997-0016-y.

Liu, B., C. Zhu, Y. Yuan, and K. Xu, 2016: Two types of interannual variability of South China Sea monsoon onset related to the SST anomalies before and after 1993/94. J. Climate, 29, 6957 6958, doi:10.1175/JCLI-D-16-0065.1.

Matsumoto, J., 1997: Seasonal transition of summer rainy season over Indochina and adjacent monsoon region. Adv. Atmos. Sci., 14, 231-245, doi:10.1007/s00376-997-0022-0.

Moron, V., A. Lucero, F. Hilario, B. Lyon, A. W. Robertson, and D. DeWitt, 2009: Spatio-temporal variability and predictability of summer monsoon onset over the Philippines. Climate Dyn., 25, 1159-1177, doi:10.1007/s00382-008-0520-5.

NCEP, 2003: The GFS Atmospheric Model. NCEP Office Note 442, 14 pp. [Available online at http://nws.noaa.gov/ost/ climate/STIP/AGFS_DOC_1103.pdf.]

Neumann, C. J., 1993: Global guide to tropical cyclone forecasting. Global Guide to Tropical Cyclone Forecasting: 1983, WMO/ TC 560, Rep. TCP-31. [Available online at http://www.wmo. int/cycloneguide/.] 
NWS/EMC, 2016: The Global Forecast System (GFS)—Global Spectral Model (GSM) (GSM version 13.0.2). NWS/Environmental Modeling Center. [Available online at http://www.emc.ncep.noaa. gov/GFS/doc.php.]

Ott, R. L., and M. T. Longnecker, 2001: An Introduction to Statistics Methods and Data Analysis. 5th ed. Duxbury Press, 1152 pp.

Ramage, C. S., 1952: Relationship of general circulation to normal weather over southern Asia and the western Pacific during the cool season. J. Meteor., 9, 403-408, doi:10.1175/ 1520-0469(1952)009<0403:ROGCTN>2.0.CO;2.

_- 1971: Monsoon Meteorology. International Geophysics Series, Vol. 15, Academic Press, 296 pp.

Ritchie, E. A., and G. J. Holland, 1999: Large-scale patterns associated with tropical cyclogenesis in the western Pacific. Mon. Wea Rev., 127, 2027-2043, doi:10.1175/1520-0493(1999)127<2027: LSPAWT > 2.0.CO;2.

RSMC, 2016: RSMC best-track data. Regional Specialized Meteorological Center-Tokyo. [Available online at http://www. jma.go.jp/jma/jma-eng/jma-center/rsmc-hp-pub-eg/besttrack. html.]

Schumacher, A. B., M. DeMaria, and J. A. Knaff, 2009: Objective estimation of the 24-h probability of tropical cyclone formation. Wea. Forecasting, 24, 456-471, doi:10.1175/2008WAF2007109.1.
Wang, L., K.-H. Lau, and C.-H. Fung, 2007: The relative vorticity of ocean surface winds from the QuikSCAT satellite and its effects on the geneses of tropical cyclones in the South China Sea. Tellus, 59A, 562-569, doi:10.1111/j.1600-0870.2007.00249.x.

$\mathrm{Wu}, \mathrm{L}$., Z. Wen, R. Huang, and R. Wu, 2012: Possible linkage between the monsoon trough variability and the tropical cyclone activity over the western North Pacific. Mon. Wea. Rev., 140, 140-150, doi:10.1175/MWR-D-11-00078.1.

_ twenty-first-century western North Pacific tropical cyclone activity using a regional model. J. Climate, 27, 3405-3424, doi:10.1175/JCLI-D-12-00830.1.

— Z. Wen, and R. Wu, 2015a: Influence of the monsoon trough on westward-propagating tropical waves over the western North Pacific. Part I: Observations. J. Climate, 28, 7108-7127, doi:10.1175/JCLI-D-14-00806.1.

- — - and - 2015b: Influence of the monsoon trough on westward-propagating tropical waves over the western North Pacific. Part II: Energetics and numerical experiments. J. Climate, 28, 9332-9349, doi:10.1175/JCLI-D-14-00807.1.

Zhou, W., and J. C.-L. Chan, 2007: ENSO and the South China Sea summer monsoon onset. Int. J. Climatol., 27, 157-167, doi:10.1002/ joc. 1380 . 